Review

\title{
Emergence of Flexible White Organic Light-Emitting Diodes
}

\author{
Dongxiang Luo ${ }^{1}$, Qizan Chen ${ }^{1}$, Baiquan Liu ${ }^{2,3, *}$ and Ying Qiu ${ }^{4, *}$ \\ 1 School of Materials and Energy, Guangdong University of Technology, Guangzhou 510006, China; \\ luodx@gdut.edu.cn (D.L.); 18219435079@163.com (Q.C.) \\ 2 LUMINOUS! Centre of Excellent for Semiconductor Lighting and Displays, School of Electrical and \\ Electronic Engineering, Nanyang Technological University, Nanyang Avenue, Singapore 639798, Singapore \\ 3 Institute of Polymer Optoelectronic Materials and Devices, State Key Laboratory of Luminescent Materials \\ and Devices, South China University of Technology, Guangzhou 510640, China \\ 4 Guangdong R\&D Center for Technological Economy, Guangzhou 510000, China \\ * Correspondence: bqliu@ntu.edu.sg (B.L.); srawoyjs@sina.com (Y.Q.)
}

Received: 29 January 2019; Accepted: 21 February 2019; Published: 22 February 2019

check for updates

\begin{abstract}
Flexible white organic light-emitting diodes (FWOLEDs) have considerable potential to meet the rapidly growing requirements of display and lighting commercialization. To achieve high-performance FWOLEDs, (i) the selection of effective flexible substrates, (ii) the use of transparent conducting electrodes, (iii) the introduction of efficient device architectures, and iv) the exploitation of advanced outcoupling techniques are necessary. In this review, recent state-of-the-art strategies to develop FWOLEDs have been summarized. Firstly, the fundamental concepts of FWOLEDs have been described. Then, the primary approaches to realize FWOLEDs have been introduced. Particularly, the effects of flexible substrates, conducting electrodes, device architectures, and outcoupling techniques in FWOLEDs have been comprehensively highlighted. Finally, issues and ways to further enhance the performance of FWOLEDs have been briefly clarified.
\end{abstract}

Keywords: flexible; OLED; white; high efficiency; exciton

\section{Introduction}

Organic light-emitting diodes (OLEDs) are now entering the mainstream display and lighting market thanks to their exceptional merits such as high efficiency, low power consumption, fast response, and their outstanding compatibility with flexible substrates [1-5]. Since the first OLED invented by Tang et al. in 1987 [6], the performance of OLEDs (e.g., external quantum efficiency (EQE), current efficiency (CE), power efficiency (PE), luminance or brightness, lifetime, and voltage) have been greatly enhanced [7-11]. Currently, it is believed that OLED technology will not only dominate the next-generation displays, but also promises to be comparable to inorganic GaN-based LEDs in the field of lighting. In addition, by dint of the reported concepts in OLEDs, many other related optoelectronic techniques have been rapidly developed [12-15]. In particular, various types of LEDs are thriving such as polymer LEDs [16-19], colloidal quantum-dot LEDs [20-23], perovskite LEDs [24-27], and colloidal quantum-well LEDs [28-30]. Thus, the further enhancement of OLED technology is also beneficial to the optoelectronic fields.

To render OLEDs more competitive than other display and lighting counterparts, flexible OLEDs have steadily attracted both scientific and industrial interest owing to their unique merits, including ultralight weight, small thickness, and suitability for roll-to-roll production [31-35]. Compared with conventional OLEDs, which are mostly manufactured on rigid glass substrates, flexible OLEDs offer the possibility of enduring vast mechanical deformation (e.g., rolling, stretching, rotating, curving, 
folding, twisting, or more complicated appearances) [36-40]. Therefore, flexible OLEDs can make our life more artistic (e.g., flexible OLEDs can be designed to apply in bags, foldable phones, curved lamps, and so on). In 1992, Heeger et al. took the first step to fabricate a flexible OLED with soluble conducting polymers on a polyethylene terephthalate (PET) substrate [41]. In 1997, Forrest et al. established the first flexible OLED with small-molecule organic materials [42]. Since then, a large amount of attention has been paid to pursuing flexible OLEDs [43]. With excellent results, Lu et al. used an efficient anode stack and a lens-based structure to unlock the full potential of a green OLED on flexible plastic, achieving a maximum PE of $290 \mathrm{~lm} \mathrm{~W}^{-1}$ [44]. Nowadays, commercial flexible OLED smartphones emerge in the market [45].

In general, white OLEDs (WOLEDs) are desirable to high-quality displays and solid-state lighting [46-51]. By carefully designing a single molecule emitter, and using complementary-color, three-color, or four-color emitters (e. g., blue/yellow, blue/green/red, blue/green/yellow/red), a great number of WOLEDs have been constructed [52-56]. In the case of traditional WOLEDs based on glass substrates, the PE has been increased from the initial value of $0.83 \mathrm{~lm} \mathrm{~W}^{-1}[57,58]$ to the current value of $123 \mathrm{~lm} \mathrm{~W} \mathrm{~m}^{-1}$ at $1000 \mathrm{~cd} \mathrm{~m}^{-2}$ (EQE: $54.6 \%$ ) in the literature [59]. For other parameters of traditional WOLEDs (e.g., lifetime [60,61], color rendering index (CRI) [62-66], correlated color temperature (CCT) [67-69], luminance [70-72], and color stability [73-76]), they have also been demonstrated to satisfy the demand of real commercialization. In terms of flexible WOLEDs (FWOLEDs), growing efforts have been taken in recent years due to the booming demand for consumer electronics. In 2005, Mikami et al. reported the first FWOLED with a PE of $4.3 \mathrm{~lm} \mathrm{~W}^{-1}$ [77]. Although the efficiency is not high due to the use of fluorescent emitters, Mikami's work starts the step towards FWOLEDs. By employing phosphorescent or thermally activated delayed fluorescence (TADF) emitters, the efficiency of FWOLEDs can be boosted [78-82]. This is because both phosphors and TADF materials can realize a theoretical unity internal quantum efficiency (IQE) via the heavy-atom effect [83-87] and small energy gap $\left(\Delta \mathrm{E}_{\mathrm{ST}}\right)$ between triplet excited state $\left(\mathrm{T}_{1}\right)$ and singlet excited state $\left(\mathrm{S}_{1}\right)$ [88-92], respectively. Hence, both singlet and triplet excitons will be harvested. Keeping these facts in mind, the efficiency of FWOLEDs (e.g., a maximum EQE of $72.4 \%$ and PE of $168.51 \mathrm{~m} \mathrm{~W}^{-2}$ ) can be as high as that of traditional WOLEDs based on glass substrates [93]. In addition, the CRI, Commission International de L'Eclairage (CIE) chromaticity coordinates and other parameters of FWOLEDs have been step-by-step improved. Furthermore, apart from bottom-emitting FWOLEDs, top-emitting FWOLEDs and transparent FWOLEDs have been demonstrated [94-96]. As a result, these structure innovations provide FWOLEDs with the ability to meet the demand of various applications.

Herein, we will summarize recent state-of-the-art strategies to develop FWOLEDs. Firstly, we will describe the fundamental concepts of flexible OLEDs. Then, we will introduce the main strategies to realize FWOLEDs. Particularly, we will comprehensively highlight the effects of flexible substrates, conducting electrodes, device architectures, and outcoupling techniques in FWOLEDs, which are expected to give a deep understanding of developing FWOLEDs. Finally, we will briefly clarify issues and ways to further enhance the performance of FWOLEDs.

\section{Fundamental Concepts of FWOLEDs}

\subsection{Flexible Substrates}

The biggest difference between conventional WOLEDs based on rigid glasses and FWOLEDs is the use of flexible substrates [97-101]. To construct a FWOLED, a flexible substrate is first selected. Then, the bottom electrode is patterned (electrode-I), as shown in Figure 1a. For different applications, electrode-I should be accordingly adjusted (e.g., electrode-I is transparent for bottom-emitting and transparent FWOLEDs but can be opague for top-emitting FWOLEDs). Subsequently, the first charge injection and transport layer, emitting layers (EMLs), the second charge injection and transport layer and the top electrode (electrode-II) are deposited. The role of charge injection and transport layers in FWOLEDs is to facilitate holes or electrons to arrive at the EMLs [102-106], which is similar to that 
of conventional WOLEDs (Figure 1b). For electrode-II, opaque and transparent metals are usually adopted for bottom-emitting FWOLEDs and top-emitting/transparent FWOLEDs, respectively. Unlike conventional WOLEDs, the electrodes, charge injection and transport layers, and EMLs in FWOLEDs will undergo mechanical deformation if the substrate is bent or stretched. As a consequence, current leakage occurs more easily in FWOLEDs compared with that of conventional WOLEDs [107-111]. Hence, flexible electrodes should be well designed.

a)

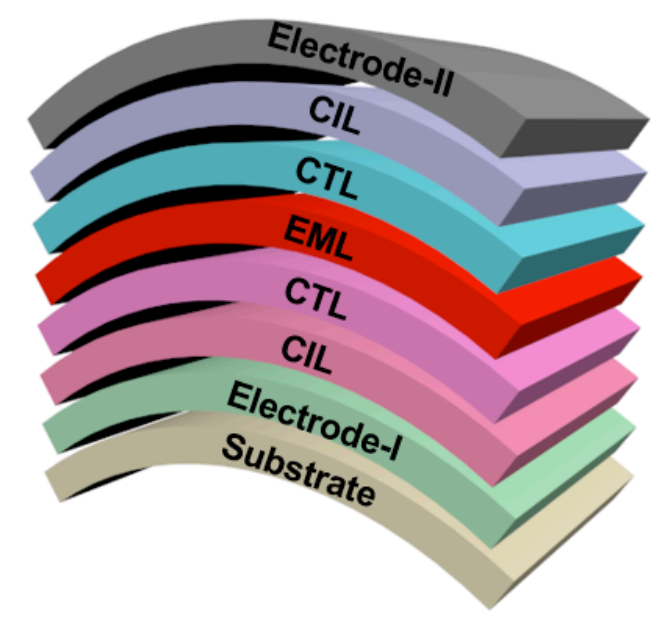

b)

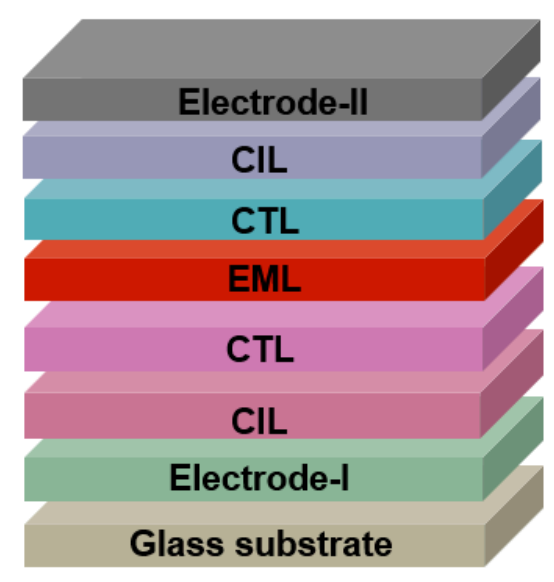

Figure 1. Diagram of the device structure of flexible white organic light-emitting diodes (FWOLEDs) (a) and conventional white organic light-emitting diodes (WOLEDs) based on rigid glass substrates (b). $\mathrm{CIL}$ is the charge injection layer, EML is the emitting layer, and CTL is the charge transport layer.

So far, several types of flexible substrates have been reported (Table 1), such as metal foils, very thin glass plastics, polydimethylsiloxane, rubber, and silk [112-116]. To be an excellent candidate material for flexible substrates, some requirements should be satisfied including remarkable mechanical deforming ability, smooth surface, good thermal durability, high oxygen and moisture blocking capability, and effective transparency for bottom-emitting and transparent FWOLEDs [117-119]. Among flexible substrates, although metal foils can undergo high working temperatures, the relatively heavy weight, rough surface, and insulating layers located between substrates and devices complicate FWOLEDs. Additionally, the intrinsic opaque property of metal foils restricts the applications in bottom-emitting and transparent FWOLEDs. In the case of thin glasses, despite good thermal durability, the brittle and fragile characteristics hinder the further development of flexible glass substrates. Therefore, considering the trade-off between cost and performance, plastics-based flexible substrates have been aggressively explored, although thermal durability is not good enough. For example, PET, polyethylene naphthalate (PEN), polyimide (PI), and polyethersulfone (PES) are the most widely adopted flexible plastic substrates for LEDs [120-123].

Table 1. Summarized performances for the commonly used flexible substrates.

\begin{tabular}{cccccccc}
\hline Substrates & Thickness & Weight & Transparency & Surface & Flexibility & Thermal Durability & Cost \\
\hline Metals & Thin & Heavy & Poor & Rough & Good & High & High \\
Glasses & Thin & Moderate & High & Moderate & Poor & High & High \\
Plastics & From thin to thick & Light & High & Smooth & Good & Low & Low \\
\hline
\end{tabular}

\subsection{Conducting Electrodes}

For bottom-emitting and transparent FWOLEDs, electrode-I should be of outstanding optical transparency (e.g., a transmittance of $>90 \%$ in the visible regime), good electrical conductivity (e.g., a sheet resistance of $<20 \Omega \mathrm{sq}^{-1}$ ), and mechanical flexibility. To date, indium tin oxide 
(ITO) is the most commonly used electrode. However, the mechanical flexibility of ITO is not satisfactory enough. Thus, a large number of efforts have been made to replace ITO with metal nanowires or grids, carbon-based materials (e.g., graphene, carbon nanotubes, reduced graphene oxide), conducting polymers, and so on [124-128]. In particular, the transmittance of graphene films greatly rely on the crystal quality. As an excellent result, a transmittance of $>97.7 \%$ can be achieved for monolayer graphene [97]. In addition, because of the low sheet resistance, high transparency, high flexibility, and the low temperature solution-processed fabrication processes, metal nanowires are promising to be electrode-I [129]. Particularly, silver nanowire is the most broadly employed metal nanowire, since it can form a high-quality ink by uniformly dispersing into ethanol. In addition, silver nanowires can break the waveguide mode and the total internal reflection, enhancing the outcoupling efficiency [130-132]. However, the cost and availability of silver means that it is not ideal for widespread commercialization. As an alternative, attention has been paid to copper nanowires, because cooper has a relatively low price and possesses high conductivity next to silver (e.g., copper is 1000 times more abundant and the cost is only 1\% compared with silver) [133-136]. For metal grids, silver and copper are also the most widely exploited elements. In addition, carbon-based materials have been intensively investigated owing to the ease of fabrication and low cost. However, the resistance of carbon-based materials is relatively high, presenting a challenge for the applications. In terms of conducting polymers (e.g., the well-known poly(3,4-ethylenedioxythiophene)/polystyrenesulfonate (PEDOT:PSS)), the inherently limited conductivity is an obstacle for the further development [137].

On the other hand, in terms of top-emitting FWOLEDs, electrode-I should exhibit high reflectivity when it is deposited on thin glass or plastic substrates. Owing to the high electrical conductivity and reflectivity, silver has been extensively utilized as the anode in top-emitting devices [138]. However, the work function of silver is very low $(4.3 \mathrm{eV})$. Hence, interface modifying layers (e.g., molybdenum oxide, 1, 4, 5, 8, 9, 11-hexaazatriphenylene hexacarbonitrile (HAT-CN), p-doping technique) are usually introduced to reduce the hole barrier between the anode and hole transport layer, lowering the voltages [139]. For metal foil based flexible substrates, the highly reflective distributed Bragg reflector (DBR) has been reported to be a good candidate for the substrate insulating layer for top-emitting OLEDs [140]. In addition, many composite electrodes have also been explored such as an $\mathrm{AuCl}_{3}$-modied graphene electrode [141], silver-nanoparticles modified graphite electrode [142], $\mathrm{ZnO} / \mathrm{Ag} / \mathrm{ZnO}$ nanofilm electrode [143], and so on [144-149].

\subsection{Device Architectures}

To guarantee the high-performance of FWOLEDs, effective device architectures are needed. Owing to the effect of spin statistics, singlets and triplets will be formed with a ratio of 1:3 upon hole meeting electrons [150-154]. For fluorophors, singlets rapidly decay with the prompt nanoseconds fluorescence, while the radiative triplets decay is spin forbidden [155-158]. Thus, the maximum IQE of fluorescent WOLEDs is only $25 \%$. By selecting phosphors or TADF emitters, the IQE of WOLEDs can be as high as $100 \%$ due to the harvest of both singlets and triplets [159-162]. According to the employed emitters, WOLEDs can be classified into four types, i.e., fluorescent WOLEDs, phosphorescent WOLEDs, TADF WOLEDs, and the so-called fluorescent/phosphorescent hybrid WOLEDs [163-167].

After the selection of emitters, the manipulation of charge and exciton distribution is key to achieve high performance [168-172]. This is because each process of charge injection, charge transport, exciton generation, exciton recombination, exciton radiative or nonradiative decay, exciton diffusion, exciton harvest, and energy transfer will affect the device performance [173-177]. As a matter of fact, a great plenty of efficient device design concepts have been reported to manipulate the charge and exciton distribution. For example, Zhu et al. designed a smart design of the emissive zone structure to make full use of generated excitons, realizing a phosphorescent WOLED with $>20 \%$ EQE [178]. Sun et al. used 4,4'-N, $\mathrm{N}^{\prime}$-dicarbazole-biphenyl (CBP) as the host and interlayer to harness all excitons, demonstrating a hybrid WOLED with an EQE of 21.2\% [179]. By precisely allocating excitons, TADF 
WOLEDs with $>20 \%$ EQE have also been developed [180]. In particular, since a blue fluorescent emitter cannot harvest triplets, the charge and exciton distribution should be carefully manipulated in hybrid WOLEDs, otherwise exciton quenching will occur between fluorophors and phosphors [181-185]. To overcome these obstacles, the introduction of interlayer or the adoption of blue fluorophor with high $\mathrm{T}_{1}$ is necessary [186-190]. By applying the efficient device architectures to FWOLEDs, high performance can be expected.

\subsection{Outcoupling Technologies}

By virtue of phosphorescent or TADF emitters, the IQE of WOLEDs can be as high as $100 \%$. However, the EQE $\left(\eta_{\text {ext }}\right)$ is also decided by the outcoupling factor, which can be defined as $[155,191]$ :

$$
\eta_{\text {ext }}=\eta_{\text {out }} \cdot r \cdot q \cdot \gamma,
$$

where $\eta_{\text {out }}$ is the outcoupling factor, $r$ is the fraction of excitons that can potentially radiatively decay, $q$ is the photoluminescence quantum efficiency of the emitter, and $\gamma$ is the charge balance. From this equation, it is easily seen that the EQE is directly proportional to the outcoupling factor. In addition, PE can be described as:

$$
\mathrm{PE} \propto \frac{\eta_{\text {out }} \cdot r \cdot q \cdot \gamma}{U}
$$

where $U$ is the voltage. Therefore, the means of enhancing the light extractive efficiency is crucial to the further improvement of EQE. Due to the wave-guiding effect, which results from the mismatch of refractive index $(n)$ among organic layers $(\mathrm{n} \approx 1.6-1.76)$, transparent electrodes (e.g., $\mathrm{n} \approx 1.8-2.2$ for ITO), glass substrate $(\mathrm{n} \approx 1.5)$, and air $(\mathrm{n} \approx 1.0)$, most photons generated by exciton recombination are trapped via the total internal reflection at interfaces inside conventional bottom-emitting OLEDs [192-194], as shown in Figure 2. According to classical ray optics theory (i.e., Snell's law), the substrate waveguide mode from the total internal reflection at the interface of glass/air and the ITO/organic waveguide mode lead to the fact that the theoretical limit for the EQE of conventional bottom-emitting OLEDs remains near $20 \%$, as described by the below equation [195]:

$$
\eta_{\text {out }}=\frac{1}{\xi n^{2}}
$$

where $n$ is the refractive index of organic material (e.g., taking the value of 1.6) and $\xi$ is a constant that depends on the dipole alignment and the geometry of the OLED device (e.g., taking the value of 2), and the isotropic emission in the organic layer and perfectly reflecting cathode are assumed. However, it is worth noting that the surface plasmon-polariton (SPP) mode associated with metallic electrode/organic interface, which is not considered by Equation (2), is also an enormous optical loss [196-198]. According to classical Snell's law with refractive indexes of air, substrate, and organic layer, the critical angle at the interface of different layers can be calculated by:

$$
n_{1} \times \sin \theta_{1}=n_{2} \times \sin \theta_{2},
$$

where $n_{1}$ and $n_{2}$ are the refractive indexes of adjacent layers and $\theta_{1}$ and $\theta_{2}$ are the critical angle at air/substrate and substrate/ITO interfaces, respectively. When the light is propagated from the optically thinner medium to optically denser medium, the light will not be reflected at the interface. Hence, $\theta_{1}$ and $\theta_{2}$ are independent of the ITO since its refractive index is higher than that of the organic layer. Apart from the SPP mode (optical loss $\approx 10 \%$ ), the generated light suffers from further three modes: (i) the external mode $(\approx 20 \%)$, where the light is emitted from OLEDs $\left(0^{\circ} \leq \theta<\theta_{1}\right)$; (ii) the substrate mode (optical loss $\approx 30 \%$ ), where the light is trapped in the substrate at the glass/air interface due to the total internal reflection and usually propagates to the edge of the glass $\left(\theta_{1} \leq \theta<\theta_{2}\right)$; and (iii) the ITO/organic mode (optical loss $\approx 40 \%$ ), where the light is trapped at the ITO/substrate interface due to the total internal reflection and dissipated by the ITO, organic, and metal cathode 
layers $\left(\theta_{2} \leq \theta<90^{\circ}\right)$. Particularly, if ITO is replaced with metallic electrodes (e.g., thin metal film, metal nanowire or grid), the ITO/organic waveguide mode will be eliminated. In such case, the SPP mode is a significant optical loss, especially for OLEDs with two metal electrodes since the SPP mode exists at the anode/organic interface and the cathode/organic interface.

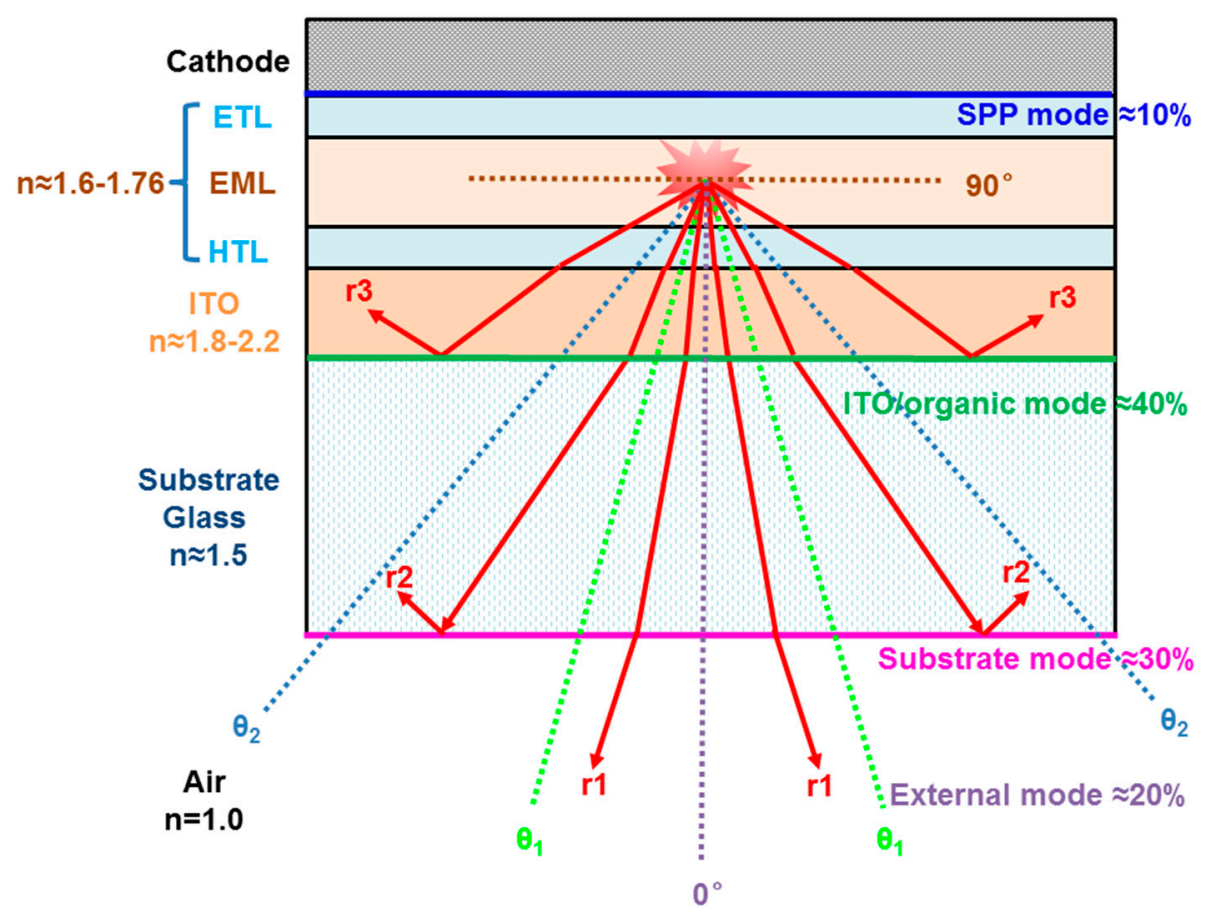

Figure 2. Schematic process of ray propagation for the planar OLED. $\mathrm{n}$ is the refractive index, ETL is electron transport layer, HTL is hole transport layer. $r 1, r 2$, and $r 3$ represent the rays propagating in the external mode $\left(0^{\circ} \leq \theta<\theta_{1}\right)$, the substrate mode $\left(\theta_{1} \leq \theta<\theta_{2}\right)$, and the indium tin oxide (ITO)/organic mode $\left(\theta_{2} \leq \theta<90^{\circ}\right)$, respectively.

In flexible OLEDs, the total internal reflection will also occur at interfaces due to the difference of refractive index [199-201]. However, for the most popular plastic substrates, their refractive index (e.g., 1.65 for PET) is higher than that of glass. Hence, the external mode, substrate mode, and ITO/organic mode are different from conventional OLEDs with glass substrates, although the SPP mode remains unchanged [202]. By using plastic substrates, the ITO/organic mode emission can be redistributed to the substrate mode. Ideally, this redistribution will completely occur if the refractive index of flexible substrates is equal to that of ITO. Then, external outcoupling technologies (e.g., scattering layers, microlens arrays) can be used to extract the substrate mode emission to the external mode, enhancing the EQE. Aside from the external outcoupling technologies, many internal outcoupling technologies (e.g., photonic crystals, microcavity structures, periodic diffraction gratings, nanoimprinted quasi-random photonic structures) have also been reported [203-207].

\section{Strategies to Achieve FWOLEDs}

\subsection{Basic Aspects of FWOLEDs}

According to the above concepts, four factors are critical to the performance of FWOLEDs, i.e., flexible substrates, conducting electrodes, device architectures and outcoupling techniques. In particular, the substrates and electrodes in FWOLEDs are unlike conventional WOLEDs based on glass substrates. Hence, many attempts have been made to resolve the issues regarding these two factors, especially flexible electrodes. For the design of device structures in FWOLEDs, the concepts in conventional WOLEDs can be used (i.e., the selection of phosphorescent or TADF emitters is essential 
to harvest the triplet excitons, and the management of charge and exciton distribution is key to the performance). In the case of outcoupling techniques, many approaches in conventional WOLEDs can be adopted for reference, particularly for the external outcoupling techniques. By carefully considering the four factors, high-performance FWOLEDs can be expected. Given that conventional WOLEDs are usually classified into four types according to the employed emitters (i.e., fluorescent, phosphorescent, TADF, and hybrid WOLEDs) [208-217], FWOLEDs can also be simply assorted via these types. In the following sections, the main strategies to develop various kinds of FWOLEDs have been highlighted from the used substrates, electrodes, and device structures to outcoupling schemes.

\subsection{FWOLEDs Based on Fluorescent Emitters}

\subsubsection{Fluorescent FWOLEDs with Indium-Zinc-Oxide Anode}

At the initial stage of the development of FWOLEDs, fluorescent emitters were usually used, leading to the waste of triplet excitons. In addition, only little attention has been paid to the outcoupling techniques. Hence, the performance of FWOLEDs is not impressive. However, compared with conventional fluorescent WOLEDs prepared on glasses, fluorescent FWOLEDs can exhibit higher efficiency due to the high-refractive-index plastic substrate which eliminates the optical loss and converts the anode/organic mode into the substrate mode. Significantly, such strategy makes a step forward in the evolution of FWOLEDs.

In 2005, Mikami et al. realized the fluorescent bottom-emitting FWOLED [77]. The flexible substrate was a heat-resistant $\left(>200{ }^{\circ} \mathrm{C}\right)$ and high-refractive-index $(\mathrm{n}=1.65)$ plastic base film with a protective layer and a thin inorganic gas barrier. The anode was the transparent indium-zinc-oxide (IZO), which was similar to ITO. As shown in Figure 3, the device structure was IZO/PEDOT:PSS/EML/2-(4-Biphenylyl)-5-(4-tert-butylphenyl-1,3,4-oxadiazole) (Bu-PBD, hole-blocking layer)/8-hydrooxyquinoline aluminum-salt (Alq ${ }_{3}$, electron transport layer)/LiF/ $\mathrm{Al}$ (cathode), where the EML was poly-(N-vinylcarbazole) (PVK): 1,1,4,4-tetraphenyl-1,3-butadiene (TPB): nile red for a FWOLED with an EQE of $2 \%$. To improve the efficiency, $0.23 \mathrm{wt} \%$ rubrene was codoped into PVK, assisting the red emission. This was because the excitation energy could be transferred to rubrene from Bu-PBD with a subsequent transfer to nile red. As a result, the FWOLED showed an EQE and PE of $4.0 \%$ and $4.3 \mathrm{~lm} \mathrm{~W}^{-1}$ at $100 \mathrm{~cd} \mathrm{~m}^{-2}$, respectively. The efficiency was improved by a factor of $10-20 \%$ compared with that of normal glass $(n=1: 52)$, since the IZO/organic mode was reduced by a factor of $46 \%$ when the normal glass substrate was replaced with a high-refractive-index $(n=1: 65)$ plastic substrate. Therefore, the key features to enhance the efficiency could be summarized: (i) the improvement of device engineering, and (ii) the utilization of high-refractive-index plastic substrate.

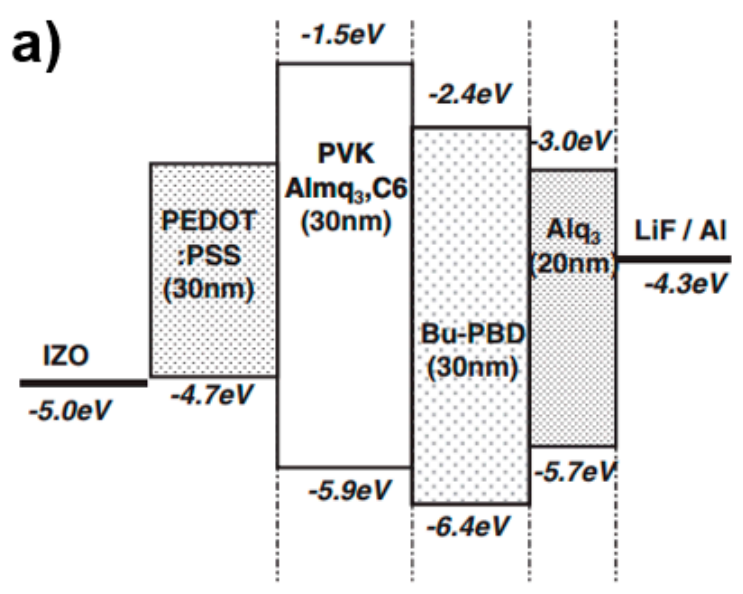

b)
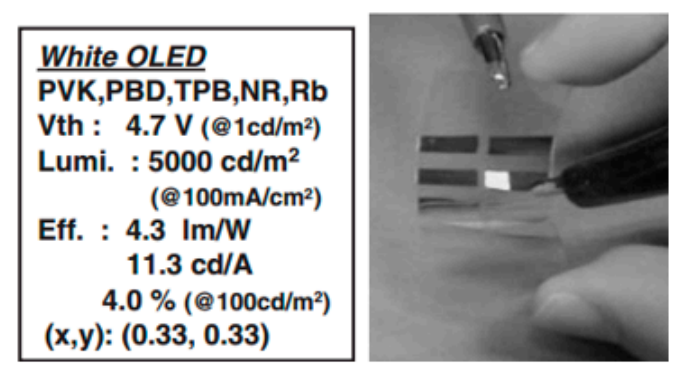

Figure 3. (a) Device structure and potential energy diagram. (b) The performance of the FWOLED and a photograph for the working FWOLED [77]. Copyright (2005) with permission from IOP Publishing. 


\subsubsection{Fluorescent FWOLEDs Using Modified ITO Anode}

If transparent conductive oxides (e.g., IZO, ITO) are functioned as the electrode on plastic substrates, the electrical conductivity may not be good enough. This is because plastics usually have a low glass transition temperature and a soft shape, which prevents transparent conductive oxides from being formed at high temperatures and making the surface smooth.

To enhance the electrical conductivity, Jou et al. built a FWOLED by utilizing effective device structure on high glass-transition plastic substrate with a thin silicon dioxide $\left(\mathrm{SiO}_{2}\right)$ pre-coat and ITO deposited using radio frequency magnetron sputtering at elevated temperature [218]. More specifically, PES was used as the flexible substrate (Figure 4). $\mathrm{SiO}_{2}$, with the optimized thickness of $15 \mathrm{~nm}$, was introduced on top between the ITO and PES substrate, improving the interfacial adhesion and enhancing resistance to the diffusion of moisture. Then, ITO was obtained using radio frequency magnetron sputtering at $200{ }^{\circ} \mathrm{C}$. After this, a WOLED structure of $N, N^{\prime}$-bis-(1-naphthy)-N,N'diphenyl-1,1'-biphenyl-4-4'-di-amine (NPB, $45 \mathrm{~nm}$, an electron-blocking and hole-transport layer)/EML (30 nm)/2,2',2"-(1,3,5-benzenetriyl)-tris(1-phenyl-1-H-benzimidazole (TPBi, $40 \mathrm{~nm}$, a hole-blocking and electron-transport layer)/LiF (1 nm)/Al (150 nm) was proposed, where the EML was 10,10'-di(biphen-4-yl)-9,9'-bianthracene (BANE): $0.05 \mathrm{wt} \%$ red dye 4-(dicyanomethylene)-2-methyl-6-(julolidin-4-ylethenyl)-4H-pyran (DCM2) in a single EML. As a result, the FWOLED showed a PE of $6.5 \mathrm{~lm} \mathrm{~W} \mathrm{~m}^{-1}$ at $800 \mathrm{~cd} \mathrm{~m}^{-2}$ and a maximum EQE of $3.2 \%$ with a pure-white light with chromaticity coordinates $(0.321,0.339)$. The key features to realize such a FWOLED could be summarized: (i) the appropriate sputtering temperature of $200{ }^{\circ} \mathrm{C}$ for ITO ensured the pure-white emission and high electrical conductivity (e.g., the emission changes markedly from pure-white to bluish-white for ITO sputtered at $200{ }^{\circ} \mathrm{C}$ or above, the ITO films sputtered at 200 ${ }^{\circ} \mathrm{C}$ exhibited a much higher conductivity, more than two times that at room temperature); (ii) the optimized thickness of $\mathrm{SiO}_{2}$ guaranteed that the ITO film deposited on PES showed a smooth surface with a roughness of $1.4 \pm 0.01 \mathrm{~nm}$ and a low resistivity of $3.9 \times 10^{-4} \Omega \mathrm{cm}$, enhancing the efficiency.

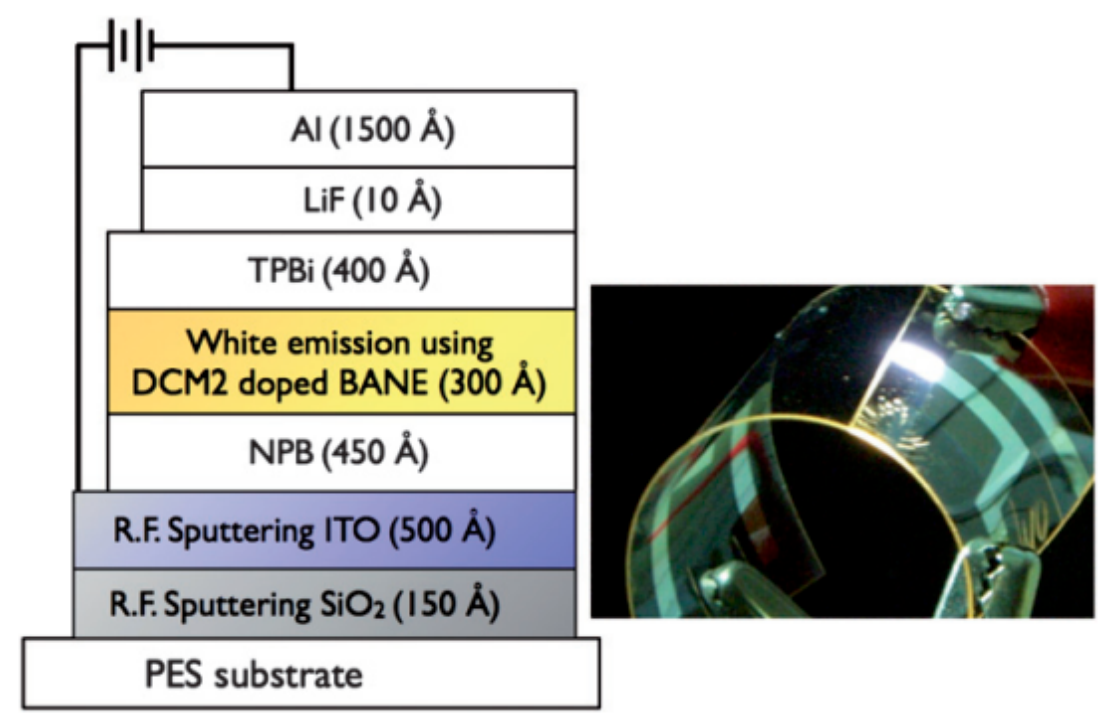

Figure 4. A schematic illustration of the structure of the FWOLED. The inset shows the photograph of the resultant device at emission under bending [218]. Copyright (2010) with permission from Royal Society of Chemistry.

\subsubsection{Fluorescent FWOLEDs Exploiting a Four-Layer Graphene Anode}

To replace the most widely used ITO anode, lots of attention has been paid to the graphene anode. This is because graphene is a flexible two-dimensional sheet of $s p^{2}$-hybridized carbon atoms, which can lower the cost and overcome the brittle issue of ITO. Before 2012, the OLEDs based on graphene 
anodes usually showed poor performance, since graphene films have a low work function $(\sim 4.4 \mathrm{eV})$ and high sheet resistance $\left(>300 \Omega \mathrm{sq}^{-1}\right)[219,220]$.

To overcome this problem, Han et al. developed a fluorescent FWOLED based on a four-layer graphene anode with a high work function $(5.95 \mathrm{eV})$ and a low sheet resistance $\left(\sim 30 \Omega \mathrm{sq}^{-1}\right)$ [221]. The key features of such modified graphene anode could be summarized: (i) graphene films were p-doped with $\mathrm{HNO}_{3}$ or $\mathrm{AuCl}_{3}$, decreasing the sheet resistance; (ii) a work function gradient from the graphene to the overlying organic layer was created by using conducting polymer compositions to modify the surface (i.e., a self-organized gradient hole injection layer composed of PEDOT:PSS and tetrafluoroethylene-perfluoro-3,6-dioxa-4-methyl-7-octenesulphonic acid copolymer, one of the perfluorinated ionomers (PFI)), which enabled holes to be injected easily into the organic layer. Then, by using a flexible PET substrate and an efficient device architecture, a FWOLED was constructed with the EML of the dopants (skyblue-emitting 4,4'-bis[2-\{4-(N,N-diphenylamino)phenyl $\}$ vinyl] (DPAVBi) and orange-red-emitting 5,6,11,12-tetraphenylnaphthacene (rubrene)) doping into separate layers in the 2-(tertbutyl)-9,10-bis(2'-naphthyl)anthracene (TBADN) host, as shown in Figure 5. As a result, the first FWOLED based on a graphene anode was developed with a maximum $\mathrm{CE}$ of $16.3 \mathrm{~cd} \mathrm{~A}^{-1}$, which was higher than that of the ITO-based WOLED $\left(10.9 \mathrm{~cd} \mathrm{~A}^{-1}\right)$.

a)

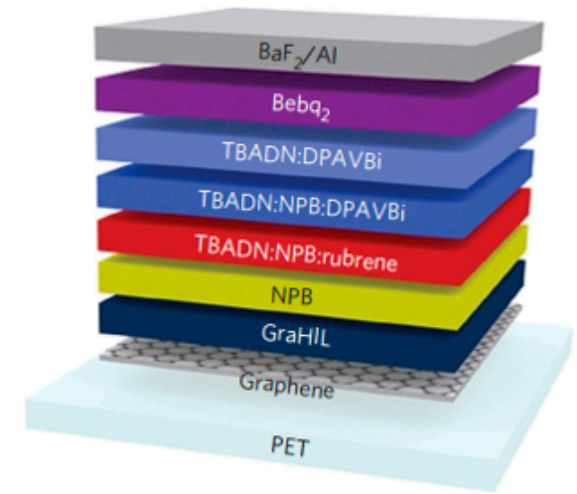

b)

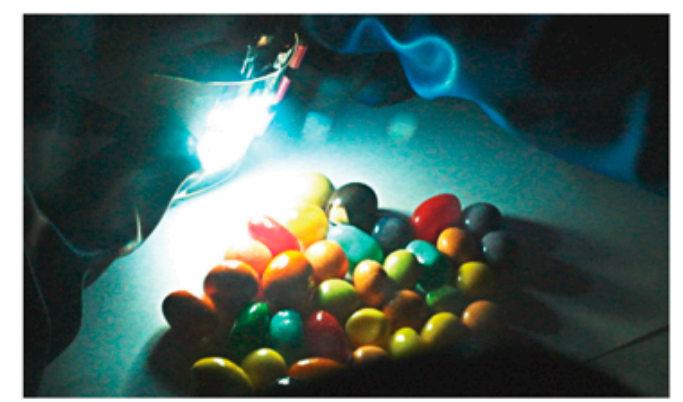

Figure 5. (a) Device structure of FWOLED with a graphene anode. (b) FWOLED lighting device with a graphene anode on a $5 \mathrm{~cm} \times 5 \mathrm{~cm}$ polyethylene terephthalate (PET) substrate [221]. Copyright (2012) with permission from Springer Nature.

\subsection{FWOLEDs Based on Hybrid Emitters}

Unlike bottom-emitting FWOLEDs, the light of top-emitting FWOLEDs is emitted from the top side. Hence, top-emitting FWOLEDs can be fabricated on opaque substrates (e.g., metal foils), in addition to thin glass and plastics. A main challenge of developing high-performance FWOLEDs is how to reduce the effect of microcavity, which is induced by the two electrodes. Especially, top-emitting FWOLEDs with high CRI are hardly achieved. To eliminate the microcavity effect, the top electrode should be as transparent as possible.

In 2011, Ji et al. used a dielectric/metal/dielectric multilayer as the top electrode, realizing the first top-emitting FWOLED with a maximum CE of $8.66 \mathrm{~cd} \mathrm{~A}^{-1}$ and CRI of 84 [222]. The key features for this FWOLED was the use of a conductive transparent cathode (i.e., $\left.\mathrm{MoO}_{3}(40 \mathrm{~nm}) / \mathrm{Ag}(17 \mathrm{~nm}) / \mathrm{MoO}_{3}(40 \mathrm{~nm})\right)$ to suppress the reflection of the metal layer and achieve a selective high transparent effect. The average transmittance of $\mathrm{MoO}_{3}(40 \mathrm{~nm}) / \mathrm{Ag}$ $(17 \mathrm{~nm}) / \mathrm{MoO}_{3}(40 \mathrm{~nm})$ in visible range was $>84 \%$, which was similar to ITO, as shown in Figure 6. In addition, the sheet resistance of $\mathrm{MoO}_{3}(40 \mathrm{~nm}) / \mathrm{Ag}(17 \mathrm{~nm}) / \mathrm{MoO}_{3}(40 \mathrm{~nm})$ was very low (i.e., $11 \Omega \mathrm{sq}^{-1}$ ). By using the flexible PET substrate, the device structure was $\mathrm{Al}$ $(100 \mathrm{~nm}) / \mathrm{MoO}_{3}(1.5 \mathrm{~nm}) / 4,4^{\prime}, 4^{\prime \prime}$-tris(3-methylphenyl-phenylamino)-tripheny-lamine (m-MTDATA, $30 \mathrm{~nm}$ )/NPB (10 nm)/4,4'-bis(2,2'-diphenylethenyl)-1,1'-biphenyl (DPVBi, $15 \mathrm{~nm}$ )/CBP (3 nm)/CBP: 
bis(2-(2-fluorophenyl)-1,3-benzothiazolato-N,C2')iridium acetylacetonate $\left[(\mathrm{F}-\mathrm{BT})_{2} \operatorname{Ir}(\mathrm{acac})\right](7 \mathrm{~nm}) / 4$, 7-diphenyl -1, 10-phenanthroline (Bphen, $30 \mathrm{~nm}) / \mathrm{LiF}(1 \mathrm{~nm}) / \mathrm{Al}(1 \mathrm{~nm}) / \mathrm{Ag}(1 \mathrm{~nm}) / \mathrm{MoO}_{3}(40 \mathrm{~nm}) / \mathrm{Ag}$ $(17 \mathrm{~nm}) / \mathrm{MoO}_{3}(40 \mathrm{~nm})$, where Al/MoO3, m-MTDATA, NPB, DPVBi, CBP: (F-BT) $)_{2} \operatorname{Ir}(\mathrm{acac})$, Bphen, and $\mathrm{LiF} / \mathrm{Al} / \mathrm{Ag} / \mathrm{M} / \mathrm{A} / \mathrm{M}$ were the anode, hole injection layer, hole transport layer, blue fluorescent EML, orange phosphorescent EML, electron transport layer, and cathode, respectively. The $\mathrm{Al}$ was used as the anode replacing the common $\mathrm{Ag}$ because $\mathrm{Al}$ film had larger phase shift on reflection than that of $\mathrm{Ag}$, while the neat CBP was introduced to separate blue and orange EMLs to avoid Dexter energy transfer between the two emitters. As a result, a top-emitting FWOLED was organized. Later, Ji et al. also demonstrated that the multilayer electrode $\left(\mathrm{Alq}_{3} / \mathrm{Ag}\right)_{2}$ was promising for FWOLEDs [223].

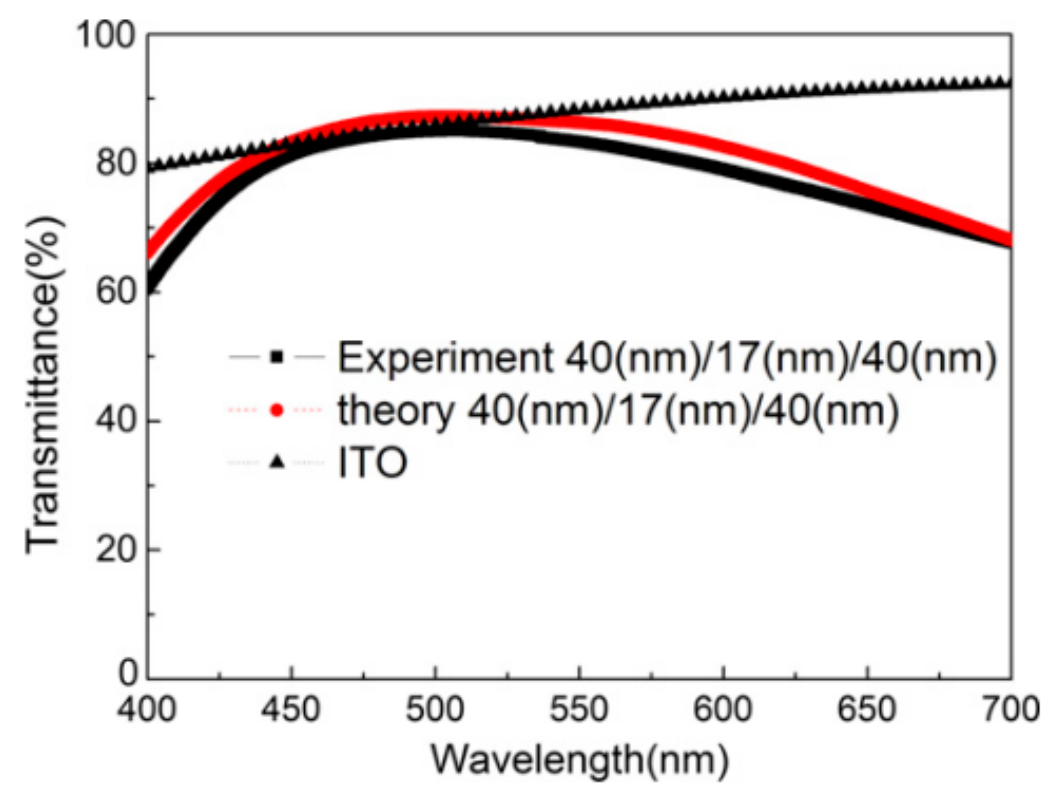

Figure 6. The measured optical transmittance curves of $\mathrm{MoO}_{3}(40 \mathrm{~nm}) / \mathrm{Ag}(17 \mathrm{~nm}) / \mathrm{MoO}_{3}(40 \mathrm{~nm})$ and ITO, the calculated optical transmittance of $\mathrm{MoO}_{3}(40 \mathrm{~nm}) / \mathrm{Ag}(17 \mathrm{~nm}) / \mathrm{MoO}_{3}(40 \mathrm{~nm})$ was also plotted [222]. Copyright (2011) with permission from Elsevier.

\subsection{FWOLEDs Based on Phosphorescent Emitters}

\subsubsection{Phosphorescent FWOLEDs Employing a Single-Layer Graphene Anode}

When electrons meet holes in OLEDs, singlet excitons and triplet excitons can be generated with the ratio of 1:3. To develop high-efficiency FWOLEDs, all generated excitons should be harvested. Hence, phosphorescent or TADF emitters are generally required, since they can harvest the triplet excitons. With the design of advanced device architecture, the maximum IQE of phosphorescent or TADF OLEDs will be unity. In addition, effective outcoupling technologies are needed to further enhance the efficiency. As a matter of fact, almost all reported high-performance FWOLEDs were established via the combination of phosphorescent/TADF emitters and outcoupling technologies.

In 2013, Li et al. reported high-efficiency FWOLEDs by using a phosphorescent device structure and effective outcoupling technology (Figure 7), yielding an EQE of external quantum efficiency $>45 \%$ at $10,000 \mathrm{~cd} \mathrm{~m}^{-2}(\mathrm{CRI}=85)$ and a PE of $80 \mathrm{~lm} \mathrm{~W}^{-1}$ at 3,000 $\mathrm{cd} \mathrm{m}^{-2}$ [224]. In this work, single-layer graphene was used as the flexible transparent anode, which was different from Han's FWOLED with four-layer graphene anode [221]. Since multiple-layer graphene required multiple graphene transfers (higher cost) and suffered from light absorption (each additional layer of graphene absorbs $\sim 3 \%$ of light across the spectrum), the use of single-layer graphene would solve these issues. To ensure that holes could be efficiently injected into EML, a p-type chemical doping was performed by soaking the graphene sample in $1 \mathrm{mg} \mathrm{ml}^{-1}$ triethyloxonium hexachloroantimonate/dichloroethene solution, producing a charge transfer complex, leading to 
an increased work function $(5.1 \mathrm{eV})$, an improved carrier density $\left(2 \times 10^{13} \mathrm{~cm}^{-2}\right)$, and a decreased sheet resistance ( $<200 \Omega$ /square). Furthermore, PEDOT:PSS $/ \mathrm{MoO}_{3}$ was utilized as the interface layer to enhance the work function of the graphene anode to $6.7 \mathrm{eV}$, which was lower than the highest occupied molecular orbital (HOMO) of the CBP based EML (6.1 eV), remarkably enhancing the hole injection. Therefore, the key feature for Li's FWOLED was the highly efficient hole injection from single-layer graphene to light-emitting layers, eliminating the efficiency roll-off due to carrier trapping, charge imbalance, and exciton quenching at the anode/organic interface. With a flexible PET substrate, the configuration was single-layer graphene anode/PEDOT:PSS $/ \mathrm{MoO}_{3} / \mathrm{CBP}: \mathrm{MoO}_{3}$ (hole injection layer)/CBP/CBP: bis[2-(2-pyridinyl-N)phenyl-C](acetylacetonato)iridium(III) [Ir(ppy) ${ }_{2}$ (acac)]: bis(2-methyldibenzo[f,h]quinoxaline) (acetylacetonate) iridium (III) [Ir(MDQ) ${ }_{2}(\mathrm{acac})$, red EML]/CBP: $\operatorname{Ir}(\text { ppy })_{2}$ (acac) (green EML)/CBP: Bis(4,6-difluorophenylpyridinato-N,C2)picolinatoiridium (Firpic, blue EML)/TPBi (electron transport layer)/LiF/Al (cathode). Then, the outcoupling method including substrates and lenses made of high index glass $(\mathrm{n}=1.80)$ was used to further enhance the efficiency, achieving a maximum EQE of $51 \%$ and a PE of $90 \mathrm{~lm} \mathrm{~W} \mathrm{~W}^{-1}$ at $1,000 \mathrm{~cd} \mathrm{~m}^{-2}$. As a result, a high-performance FWOLED was developed.

a)

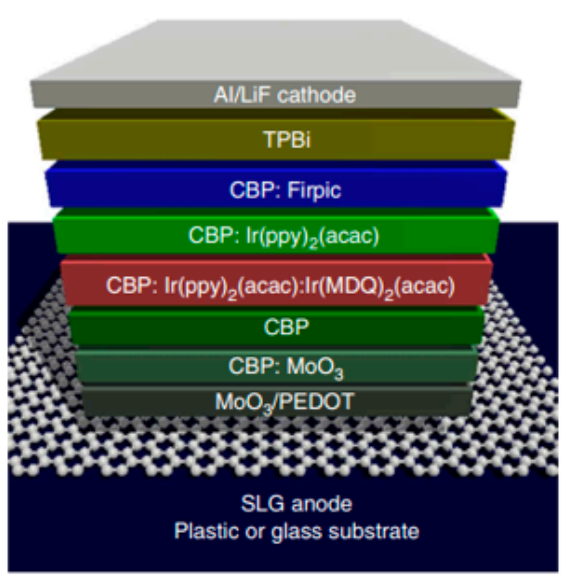

b)

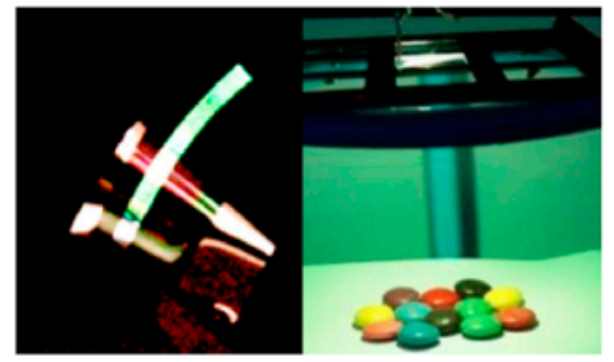

Figure 7. (a) The device structure of FWOLED, (b) photos of FWOLED and a high brightness FWOLED illuminating colored objects [224]. Copyright (2013) with permission from Springer Nature.

\subsubsection{Phosphorescent FWOLEDs Utilizing a Simplified Outcoupling Approach}

For Li's FWOLED [224], the efficiency of the FWOLED was comparable to general lighting. However, the improvement in optical outcoupling that relied on high refractive index substrates was unfavorable to low cost mass production. Furthermore, half sphere lens are usually only suitable for small-area devices, which are not practical for large-area applications. Therefore, a simplified, low-cost but effective outcoupling approach with suitability for large-area applications is beneficial to free the light trapped by the substrate of FWOLEDs.

In 2014, Liu et al. realized a FWOLED with an outcoupling film that was fabricated by dispersing $\mathrm{SiO}_{2}(\mathrm{n}=\sim 1.5$, average particle sizes of $1.5 \mu \mathrm{m})$ into SU-8 matrix with a concentration of $15 \%$, exhibiting a maximum forward-viewing PE of $101.3 \mathrm{~lm} \mathrm{~W}^{-1}$ [225]. Furthermore, the device exhibited excellent color stability with a CIE variation of $(0.004,0.005)$ when the luminance increased from 100 to $10000 \mathrm{~cd} \mathrm{~m}^{-2}$. As shown in Figure 8, with the $120 \mu \mathrm{m}$ PEN substrate, the device configuration was ITO (170 nm)/MeO-TPD: F4-TCNQ (100 nm, 4\%)/NPB (15 nm)/TCTA $(5 \mathrm{~nm}) /$ TCTA: $\operatorname{Ir}(\mathrm{dmppy})_{2}(\mathrm{dpp})(1 \mathrm{~nm}, 20 \%) /$ TCTA: FIrpic $(4 \mathrm{~nm}, 7 \%) / 26$ DCzPPy: FIrpic $(4 \mathrm{~nm}$, 20\%)/26DCzPPy: $\operatorname{Ir}(\mathrm{dmppy})_{2}$ (dpp) $(1 \mathrm{~nm}, 20 \%) / \operatorname{TmPyPB}(50 \mathrm{~nm}) / \mathrm{LiF}(1 \mathrm{~nm}) / \mathrm{Al}(200 \mathrm{~nm})$, where ITO was an anode, F4-TCNQ was tetrafluoro-tetracyanoqinodimethane, doped into $\mathrm{N}, \mathrm{N}, \mathrm{N}^{\prime}, \mathrm{N}^{\prime}$ tetrakis(4-methoxyphenyl)-benzidine (MeO-TPD), TCTA is 4,4', $4^{\prime \prime}$-tri(9-carbazoyl) triphenylamine (an exciton/electron blocking layer and a host of orange/blue emitters), $\operatorname{Ir}(\mathrm{dmppy})_{2}$ (dpp) was Bis(2-phenyl-4,5-dimethylpyridinato)[2-(biphenyl-3-yl)pyridinato] iridium(III) (an orange emitter), 
FIrpic was a blue emitter, 26DCzPPy was 2,6-bis(3-(carbazol-9-yl)phenyl)pyridine (a host of orange/blue emitters), TmPyPB was 1,3,5-tri(m-pyrid-3-yl-phenyl)benzene, LiF was an electron injection layer and $\mathrm{Al}$ was a cathode. For this structure, the main exciton generation zone was located at the TCTA/26DCzPPy interface, which was effectively broadened via the double blue EML. In addition, to stabilize the color, enhance the efficiency, and to reduce the efficiency roll-off, some device strategies were adopted, i.e., the optimized EML thickness, the orange EMLs designed to surround blue EMLs for harvesting the unused excitons, the charge transport layers of TCTA and TmPyPB having high $S_{1}$ and $T_{1}$ to confine singlets and triplets in the EML, and the reduction of charge mobility associated with host-dopant energy level difference. To further enhance the performance of FWOLEDs, an outcoupling approach was proposed by simply dispersing $\mathrm{SiO}_{2}$ into SU-8 matrix to fabricate scattering films, extracting the light trapped by the substrate. Therefore, the key features for the high performance could be summarized: (i) a multifunctional carrier- and exciton-confining structure was designed to guarantee the high efficiency and stable color; (ii) a simplified, low-cost but effective outcoupling approach with suitability for large-area applications was used to free the light trapped by the substrate.
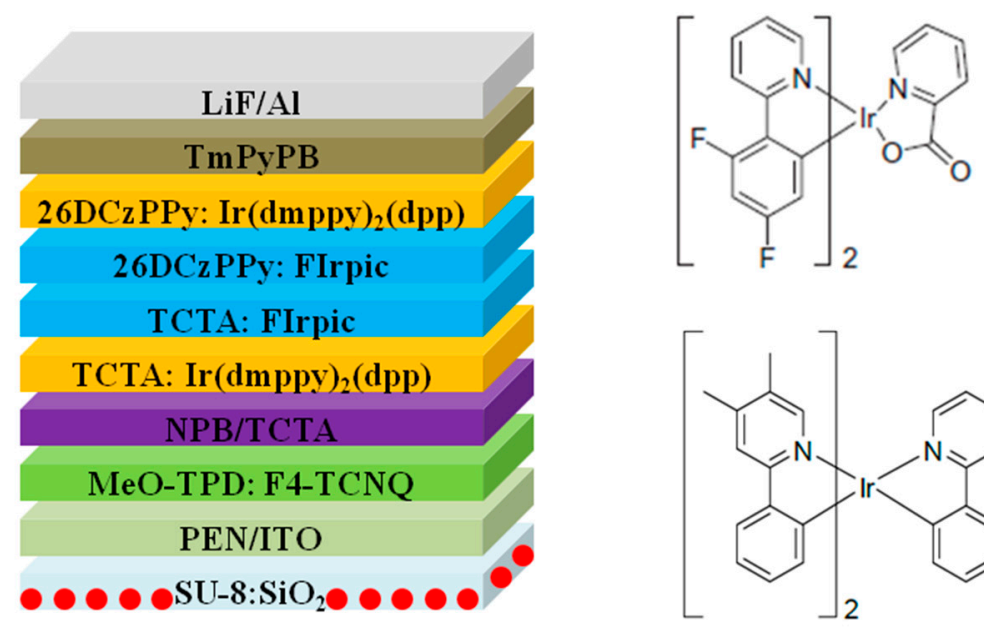

\section{FIrpic}
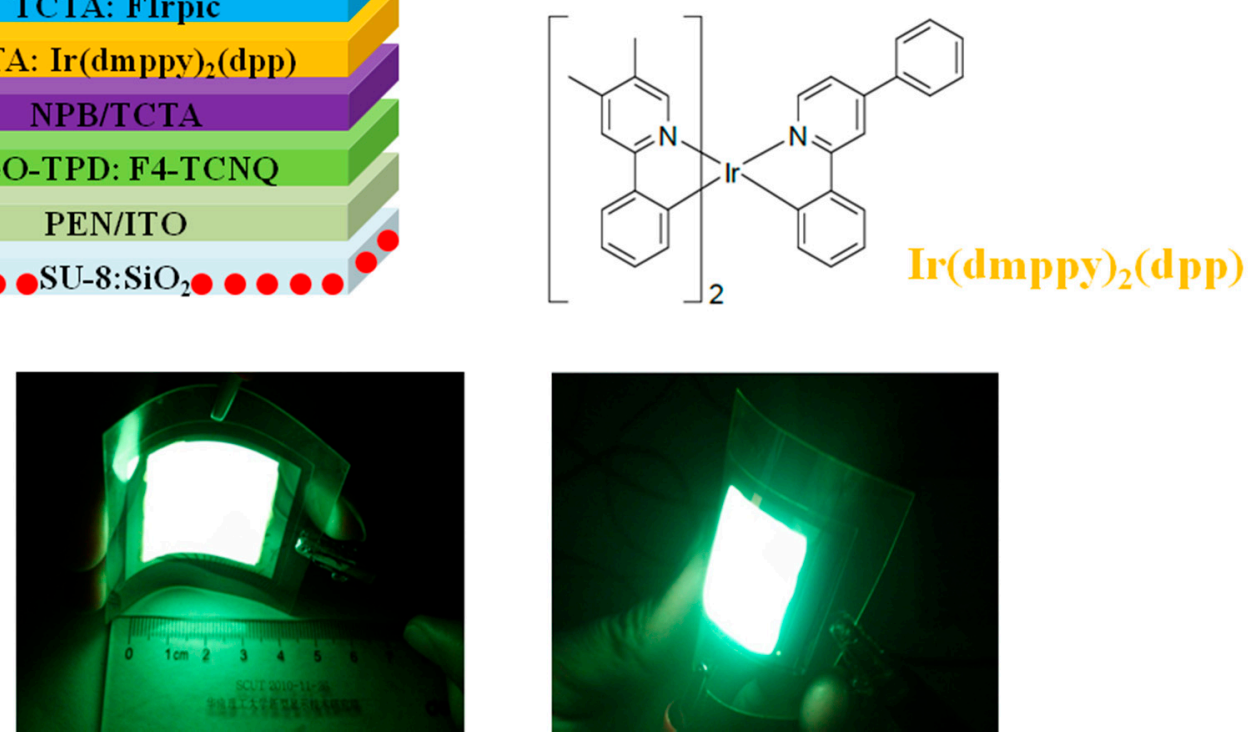

Figure 8. Top: The schematic structure of FWOLED and chemical structure of emitters. Bottom: Photographs of large-area FWOLED $(30 \mathrm{~mm} \times 30 \mathrm{~mm})$ working at $1000 \mathrm{~cd} \mathrm{~m}^{-2}$ [225]. Copyright (2014) with permission from Royal Society of Chemistry.

\subsubsection{Phosphorescent FWOLEDs Having Plastic with Embedded Ag Network Anode}

In Liu's work [225], the efficiency of the FWOLED was demonstrated to exceed $100 \mathrm{~lm} \mathrm{~W}^{-1}$. However, in addition to the limited bendability, the use of an ITO anode cannot avoid the ITO/organic waveguide mode due to the high refractive index of ITO. As a result, optical loss may limit the further enhanced efficiency of such a FWOLED. To unlock the potential efficiency, high-quality transparent conductive electrodes with superior stretchability and roll-to-roll manufacturing compatibility to replace ITO is required, apart from the feasible outcoupling technologies. Based on this strategy, FWOLEDs are expected to possess much higher efficiency. 
By combining a transparent conductor on plastic with embedded silver networks as the anode and an outcoupling structure simultaneously extracting light in waveguide and substrate modes and reducing the surface plasmonic losses, Tang et al. presented a FWOLED showing a maximum EQE of $49 \%$ and PE of $118.1 \mathrm{~lm} \mathrm{~W}^{-1}$ [226]. For the flexible OLEDs using this new anode, only a small decrease in efficiency (19\%) after 1000 bending cycles occurred. In addition, the new anode exhibited a low surface roughness to avert electrical short circuits and a lower sheet resistance in comparison with ITO at a given transparency. As shown in Figure 9, with the PET substrate, the device structure was the new anode/PEDOT:PSS/di[4-(N,N-ditolylamino)phenyl]cyclohexane (TAPC, $45 \mathrm{~nm}$,hole transport layer)/N, $\mathrm{N}^{\prime}$-Dicarbazolyl-3,5-benzene (mCP): $8 \mathrm{wt} \%$ FIrpic (19 nm, blue EML)/mCP: $6 \mathrm{wt} \%$ iridium(III) bis(4-phenylthieno[3,2-c]pyridinato-N,C2') acetylacetonate (PO-01, $1 \mathrm{~nm}$, yellow EML)/TPBi (40 nm, electron transport layer)/LiF $(1 \mathrm{~nm}) / \mathrm{Al}(100 \mathrm{~nm})$. The key features for the high light extraction efficiency were: (i) the well matched refractive index of plastic with embedded Ag networks $(n=1.49)$ to PEDOT:PSS $(n=1.46)$ and organic layers $(n=1.75)$, eliminating the photon flux trapped in the ITO/organic waveguide mode, enhancing the light from organic EMLs into the substrate; (ii) a light outcoupling structure by nanoimprinting the PEDOT:PSS layer with deterministic aperiodic nanostructures to promote the extraction of light originally trapped in the organic waveguide mode into the plastic substrate; and (iii) a microlens array applied to the plastic substrate to extract light from the substrate to the air. Therefore, a high-efficiency FWOLED has been developed. With the similar device architecture and a new metal-dielectric composite electrode, Tang et al. also reported a highly efficient FWOLED without outcoupling structure, exhibiting a maximum EQE of $47.2 \%$ and PE of $112.4 \mathrm{~lm} \mathrm{~W}^{-1}$ [227].
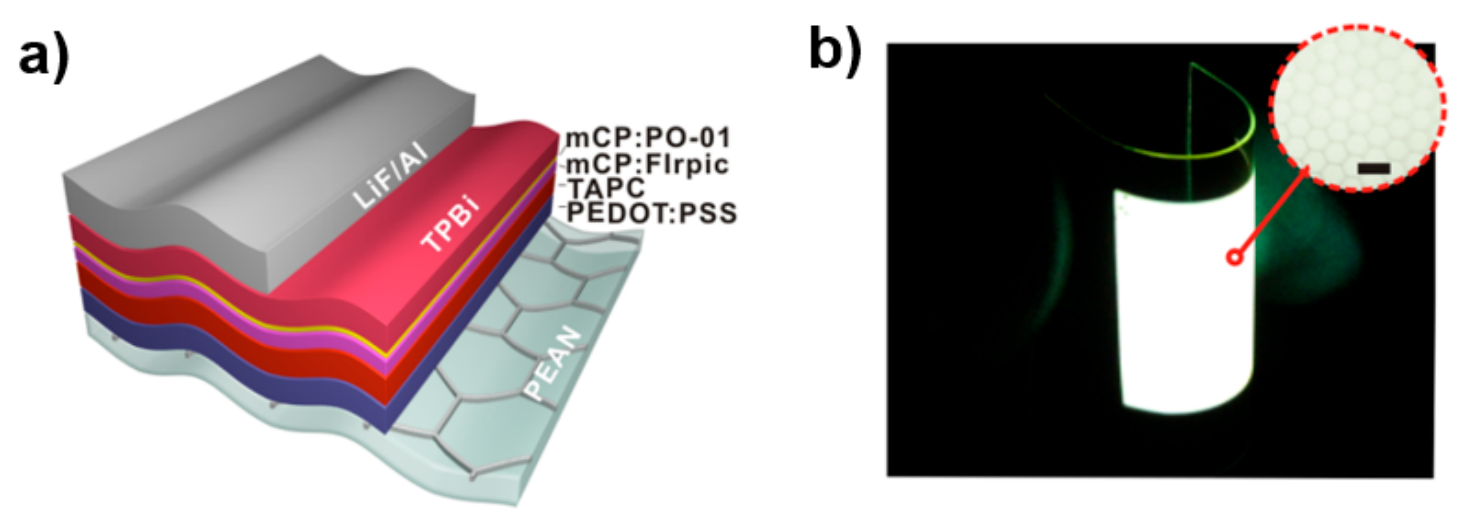

Figure 9. (a) Schematic of FWOLED device structure using plastic with embedded Ag networks as anode. (b) Photograph of a large-area FWOLED $(50 \mathrm{~mm} \times 50 \mathrm{~mm})$. Inset: the magnified image taken with an optical microscope (scale bar $=3.00 \mu \mathrm{m}$ ) [226]. Copyright (2014) with permission from American Chemical Society.

\subsubsection{Transparent Phosphorescent FWOLEDs Possessing Plastic with Embedded Ag Grid Anode}

The motivation for using metal-dielectric composite electrodes is that they are effective in terms of mechanical flexibility, electrical conductivity, optical transparency, and large-area film uniformity. Particularly, plastic with embedded Ag grid anodes can minimize the microcavity effect in OLEDs, which is favorable for high color quality. Another significant application for FWOLEDs is the development of transparent devices. However, it is challenging to realize the high-performance transparent FWOLEDs, considering three crucial aspects are required to be simultaneously addressed, i.e., transparent electrodes, device architectures, and outcoupling methods.

To unlock the great potential of transparent FWOLEDs, Tang et al. recently reported a device that could collectively reduce ohmic losses and release the trapped photons, achieving a maximum EQE of $72.4 \%$ and PE of $168.5 \mathrm{~lm} \mathrm{~W}^{-1}$ with a CRI of 84.5 [93]. For the bottom transparent electrode, an embedded silver grid with hexagonal structure on a PET substrate was employed, then $80 \mathrm{~nm}$ PEDOT:PSS was spin-coated onto this PET to promote hole injection into an organic stack with triple 
electrophosphorescent EMLs, as shown in Figure 10. Such metal-dielectric composite electrodes were excellent alternatives due to their high performance in terms of efficiency and mild angular dependence on emission spectra. In addition, the sheet resistance of this electrode was only $4.7 \Omega \mathrm{sq}^{-1}$, improving the electrical behaviors due to the reduced ohmic loss. On the other hand, the top transparent electrode was composed of $1 \mathrm{~nm}$ LiF electron-injection layer/1.5 nm Al seeding layer/15 nm Ag conductive layer/70 nm NPB optical coupling layer. Therefore, these two transparent electrodes ensured that the white emission could be emitted from both sides. With regards device architecture, an efficient organic emitter with negligible energy loss during electron-photon conversion was designed, i.e., the bottom electrode/PEDOT:PSS/TAPC (50 nm) as the hole transport layer/TCTA (5 nm) as the electron blocking layer/mCP: $6 \mathrm{wt} \% \operatorname{Ir}(\mathrm{MDQ})_{2}(\mathrm{acac})(7 \mathrm{~nm})$ for red emission $/ \mathrm{mCP}: 8 \mathrm{wt} \% \operatorname{Ir}(\mathrm{ppy})_{2}(\mathrm{acac})(3.5 \mathrm{~nm})$ for green emission/mCP: $8 \mathrm{wt} \%$ FIrpic $(5.5 \mathrm{~nm})$ for blue emission/TmPyPB $(60 \mathrm{~nm})$ as the electron transport/hole blocking layer/the top electrode. To further increase the efficiency, an outcoupling approach was used to suppress the substrate mode by employing an additional external moth-eye structure. Therefore, a highly efficient transparent FWOLED was presented (the maximum PE/EQE were $103.9 \mathrm{~lm} \mathrm{~W}^{-1} / 43.7 \%$ and $64.6 \mathrm{~lm} \mathrm{~W}^{-1} / 28.7 \%$ for the bottom and top side, respectively). The key feature of this transparent FWOLED was the integration of bioinspired moth-eye nanostructures into the transparent electrodes, which enabled the broadband angle independent outcoupling enhancement of the waveguide light and suppressed the surface plasmonic loss at the metal/dielectric interface with no impact on electrical properties.
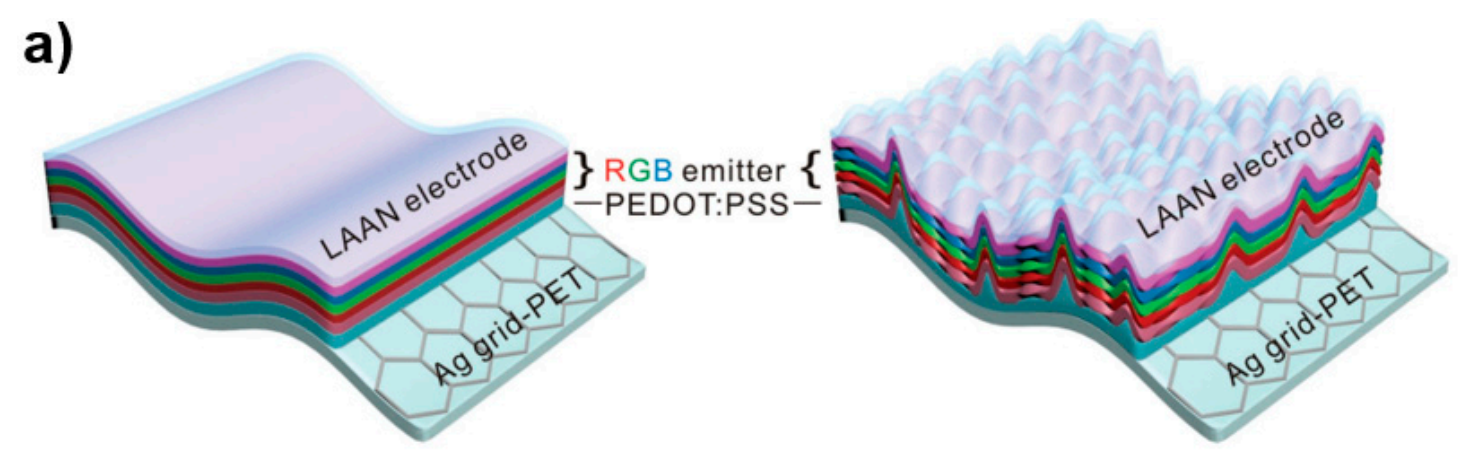

b)
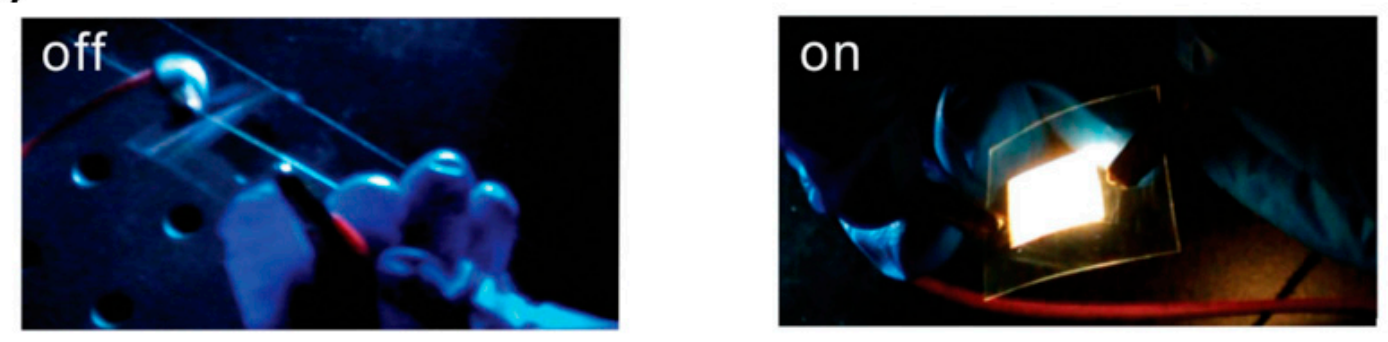

Figure 10. (a) Schematic of FWOLEDs on plastic without and with internal moth-eye outcoupling structure. (b) Photographs of a FWOLEDs in off and on states [93]. Copyright (2018) with permission from John Wiley and Sons publisher.

From the development of FWOLEDs, it can be easily noted that the innovation of flexible electrodes is a hot topic, which is expected to replace the well-known ITO electrode. In fact, significant progress has been made on flexible electrodes. Apart from the above mentioned flexible electrodes, many efficient electrodes have also been reported. For example, Koo et al. developed a bottom-emitting FWOLED by using a multilayered metal stack anode of $\mathrm{Ni} / \mathrm{Ag} / \mathrm{Ni}$ treated with oxygen plasma for $60 \mathrm{~s}$, obtaining a maximum EQE of 5.85\% [228]. Chen et al. reported a FWOLED by modifying the graphene anode surface with PSS to improve the air-stability/hole-injection ability and reduce the leakage current, achieving a maximum PE of $128.2 \mathrm{~lm} \mathrm{~W}^{-1}$ and EQE of $99.5 \%$ [229]. In brief, the 
future target for flexible electrodes is that they should have outstanding optical transparency/electrical conductivity/mechanical flexibility and be accessible to large-scale manufacturing with low cost.

\section{Summary and Outlook}

Since FWOLEDs are not only compatible with the technology of conventional WOLEDs based on rigid glass substrates but also undergo remarkable mechanical deformation, these excellent characteristics mean that FWOLEDs are very promising for next-generation displays and lighting. Nowadays, the efficiency of state-of-the-art FWOLEDs is comparable to that of the best traditional WOLEDs based on glass substrate and ITO anode. In this review, we have mainly focused on recent advances in FWOLEDs. Particularly, we have emphasized representative FWOLEDs based on fluorescent, hybrid, and phosphorescent emitters. The detailed performances for FWOLEDs have been described in Table 2.

Table 2. Summarized performances for representative FWOLEDs.

\begin{tabular}{|c|c|c|c|c|c|c|c|}
\hline WOLEDs $^{a}$ & Year $^{b}$ & $\begin{array}{c}\mathrm{V}_{\text {on }}{ }^{\mathrm{c}} \\
(\mathrm{v})\end{array}$ & $\underset{(\%)}{\mathrm{EQE}_{\max } /_{1000} \mathrm{~d}}$ & $\begin{array}{l}\mathrm{PE}_{\max } /_{1000} \\
\left(\operatorname{lm} W^{-1}\right)\end{array}$ & $\begin{array}{l}\mathrm{CE}_{\max } /_{1000} \mathrm{f} \\
\left(\mathrm{cd} \mathrm{A} A^{-1}\right)\end{array}$ & CIE $\mathrm{g}$ & $\mathrm{CRI}^{\mathrm{h}}$ \\
\hline Ref. [77] & 2005 & 4.7 & $4.0 /-$ & $4.3 /-$ & $11.3 /-$ & $(0.33,0.33)$ & - \\
\hline Ref. [218] & 2010 & 4.0 & $3.2 /-$ & $6.5 /-$ & $-/-$ & $(0.32,0.34)$ & - \\
\hline Ref. [221] & 2012 & $\sim 2.8$ & $-/-$ & $-/-$ & $16.3 /-$ & $(0.32,0.42)$ & - \\
\hline Ref. [222] & 2011 & $\sim 4.4$ & $-/-$ & $-/-$ & $8.66 /-$ & $(0.43,0.39)$ & 84 \\
\hline Ref. [224] & 2013 & - & $51 /-$ & $90 / 90$ & $120 /-$ & - & 85 \\
\hline Ref. [225] & 2014 & 3.1 & $-/-$ & $101.3 / 58.2$ & $96.8 / 79.1$ & $(0.32,0.47)$ & 52 \\
\hline Ref. [226] & 2014 & - & $49 / 46.3$ & $118.1 / 106$ & $-/ 121.5$ & - & - \\
\hline Ref. [93] & 2018 & - & $72.4 / 69.4$ & $168.5 / 142.5$ & $-/-$ & - & 84.5 \\
\hline
\end{tabular}

${ }^{a}$ Representative FWOLEDs. ${ }^{b}$ The year for the reported FWOLEDs. ${ }^{c}$ Turn-on voltage. ${ }^{d}$ Peak external quantum efficiency (EQE)/EQE at $1000 \mathrm{~cd} \mathrm{~m}^{-2}$. e Peak power efficiency (PE)/PE at $1000 \mathrm{~cd} \mathrm{~m}^{-2} .{ }^{\mathrm{f}}$ Peak current efficiency (CE)/CE at $1000 \mathrm{~cd} \mathrm{~m}^{-2}$. g Commission International de L'Eclairage (CIE) coordinates at $\sim 1000 \mathrm{~cd} \mathrm{~m}^{-2}$. ${ }^{\mathrm{h}}$ Peak color rendering index (CRI).

After about 14 years of development, the performance of FWOLEDs has been enhanced step-by-step. In particular, their performance has been greatly boosted by the combination of phosphorescent device architectures and efficient outcoupling technologies. With the evolution of flexible transparent electrodes, the performance of FWOLEDs has been further improved. Although negligible attention has been paid to FWOLEDs based on TADF emitters thus far, it can be easily predicted that such types of FWOLEDs will show high performance via effective device architectures due to the 100\% triplet-harvesting efficiency of TADF emitters, which is similar to phosphors [230-232]. To date, there are still many challenges hindering the development of commercial productions such as the efficiency, efficiency roll-off, angular color stability, cost, and particularly operational stability. For the issue of efficiency, since the theoretical efficiency limit of WOLEDs is $248 \mathrm{~lm} \mathrm{~W}^{-1}$, there is much room for FWOLEDs to be enhanced [233]. According to Equation (1), the EQE is determined by four factors. For the outcoupling schemes, although several effective methods have been reported to enhance the efficiency of FWOLEDs, there is still a long way to go regarding compatibility with large-area productions and stabilizing the angular colors [234-236]. To design good device architectures, the charge and exciton distribution should be carefully manipulated, which is beneficial to efficiency, efficiency roll-off, color stability, and lifetime [237-240].

For the issue of lifetime, it is a key factor in determining whether FWOLEDs can meet the demands of commercialization. Generally, a lifetime of $\geq 10,000 \mathrm{~h}$ at $\geq 1000 \mathrm{~cd} \mathrm{~m}^{-2}$ is required for the commercial applications of WOLEDs. However, it is worth pointing out that the working stability of FWOLEDs has been negligibly reported, which may be attributed to the short lifetime of FWOLEDs. For example, 5.2 $\mathrm{h}$ at an initial luminance of $1000 \mathrm{~cd} \mathrm{~m}^{-2}$ was obtained in Liu's FWOLEDs [225]. One of the reasons for the poor lifetime is that it is still a huge obstacle to realize stable phosphorescent WOLEDs, since blue phosphors easily suffer chemical degradation during device operation. However, blue phosphors are required for the reported highly efficient FWOLEDs [93,224-226]. To alleviate this difficulty, the use of 
hybrid or TADF device structures may be helpful [241-243]. Another strategy to prolong the lifetime is the introduction of advanced flexible encapsulation techniques, since OLEDs are sensitive to moisture and oxygen. By reducing the water vapor transmission rate of the encapsulation (e.g., multilayers fabricated by $\mathrm{Al}_{2} \mathrm{O}_{3}$ and rapid $\mathrm{SiO}_{2}$ atomic layer deposition [244] and organic-inorganic multilayer structures [245]) to the ideal encapsulating barriers $\left(10^{-6} \mathrm{~g} / \mathrm{m}^{2} /\right.$ day) [246], much longer lifetime can be expected. To make FWOLEDs more competitive, researchers should pay more attention to lifetime. After solving the mentioned issues, the prospect for mass production of FWOLEDs will be bright, and the proposed solutions are also beneficial to the related optoelectronic fields (e.g., display, lighting, laser, solar cell, photodetector, thin film transistor, and sensor) [247-251].

Acknowledgments: The authors are grateful to the National Natural Science Foundation of China (Grant No. 61704034), the Key Platforms and Research Projects of Department of Education of Guangdong Province (Grant No. 2016KTSCX034), the Guangdong Science and Technology Plan (Grant No. 2017B010123002), and the Natural Science Foundation of Guangdong Province (Grant No. 2018A0303130199 and 2017A030313632).

Conflicts of Interest: The authors declare no conflicts of interest.

\section{References}

1. Yang, X.; Zhou, G.; Wong, W.-Y. Functionalization of Phosphorescent Emitters and Their Host Materials by Main-Group Elements for Phosphorescent Organic Light-Emitting Devices. Chem. Soc. Rev. 2015, 44, 8484-8575. [CrossRef] [PubMed]

2. Jou, J.-H.; Kumar, S.; Agrawal, A.; Li, T.-H.; Sahoo, S. Approaches for Fabricating High Efficiency Organic Light Emitting Diodes. J. Mater. Chem. C 2015, 3, 2974-3002. [CrossRef]

3. Luo, D.; Xiao, P.; Liu, B. Doping-Free White Organic Light-Emitting Diodes. Chem. Rec. 2018. [CrossRef] [PubMed]

4. Fan, C.; Yang, C. Yellow/orange emissive heavy-metal complexes asphosphors in monochromatic and white organic light-emitting devices. Chem. Soc. Rev. 2014, 43, 6439-6469. [CrossRef]

5. Tyan, Y.S. Organic Light-Emitting-Diode Lighting Overview. J. Photonics Energy 2011, 1, 011009. [CrossRef]

6. Tang, C.W.; VanSlyke, V.A. Organic Electroluminescent Diodes. Appl. Phys. Lett. 1987, 51, 913-915. [CrossRef]

7. Ma, Y.; Zhang, H.; Shen, J.; Che, C. Electroluminescence from triplet metal-ligand charge-transfer excited state of transition metal complexes. Synth. Met. 1998, 94, 245-248. [CrossRef]

8. Baldo, M.A.; O’brien, D.F.; You, Y.; Shoustikov, A.; Sibley, S.; Thompson, M.E.; Forrest, S.R. Highly Efficient Phosphorescent Emission From Organic Electroluminescent Devices. Nature 1998, 395, 151-154. [CrossRef]

9. Al-Asbahi, B.A. Influence of $\mathrm{SiO}_{2} / \mathrm{TiO}_{2}$ Nanocomposite on the Optoelectronic Properties of PFO/MEH-PPV-Based OLED Devices. Polymers 2018, 10, 800. [CrossRef]

10. Liu, B.; Gao, D.; Wang, J.; Wang, X.; Wang, L.; Zou, J.; Ning, H.; Peng, J. Progress of White Organic Light-Emitting Diodes. Acta Phys. Chim. Sin. 2015, 31, 1823-1852.

11. Seifert, R.; Moraes, I.R.D.; Scholz, S.; Gather, M.C.; Lüssem, B.; Leo, K. Chemical Degradation Mechanisms of Highly Efficient Blue Phosphorescent Emitters Used for Organic Light Emitting Diodes. Org. Electron. 2013, 14, 115-123. [CrossRef]

12. Shi, Z.; Li, S.; Li, Y.; Ji, H.; Li, X.; Wu, D.; Xu, T.; Chen, Y.; Tian, Y.; Zhang, Y.; et al. Strategy of solution-processed all-inorganic heterostructure for humidity/temperature-stable perovskite quantum dot light-emitting diodes. ACS Nano 2018, 12, 1462-1472. [CrossRef]

13. Zhu, L.P.; Li, X.D.; Song, C.J.; Liu, X.H.; Wang, Y.-C.; Zhang, W.J.; Fang, J.F. Cathode modification in planar hetero-junction perovskite solar cells through a small-molecule zwitterionic carboxylate. Org. Electron. 2017, 48, 204-210. [CrossRef]

14. Zhang, L.Z.; Zhou, X.Y.; Zhong, X.W.; Cheng, C.; Tian, Y.Q.; Xu, B.M. Hole-transporting layer based on a conjugated polyelectrolyte with organic cations enables efficient inverted perovskite solar cells. Nano Energy 2019, 57, 248-255. [CrossRef]

15. Huang, J.; Xiang, S.H.; Yu, J.S.; Li, C.-Z. Highly efficient prismatic perovskite solar cells. Energ. Environ. Sci. 2019. [CrossRef]

16. Ying, L.; Ho, C.L.; Wu, H.; Cao, Y.; Wong, W.Y. White Polymer Light-Emitting Devices for Solid-State Lighting: Materials, Devices, and Recent Progress. Adv. Mater. 2014, 26, 2459-2473. [CrossRef] 
17. Zou, J.; Wu, H.; Lam, C.S.; Wang, C.; Zhong, C.; Hu, S.; Ho, C.L.; Zhou, G.J.; Wu, H.; Choy, W.C.; et al. Simultaneous Optimization of Charge-Carrier Balance and Luminous Efficacy in Highly Efficient White Polymer Light-Emitting Devices. Adv. Mater. 2011, 23, 2976-2980. [CrossRef]

18. Niu, Y.H.; Liu, M.; Ka, J.W.; Bardeker, J.; Zin, M.; Schofield, Y.; Chi, Y.; Jen, A.K.-Y. Crosslinkable Hole-Transport Layer on Conducting Polymer for High-Efficiency White Polymer Light-Emitting Diodes. Adv. Mater. 2010, 9, 300-304. [CrossRef]

19. Wang, H.; Meng, L.Q.; Shen, X.X.; Wei, X.F.; Zheng, X.L.; Lv, X.P.; Yi, Y.P.; Wang, Y.; Wang, P.F. Light-Emitting Diodes: Highly Efficient Orange and Red Phosphorescent Organic Light-Emitting Diodes with Low Roll-Off of Efficiency using a Novel Thermally Activated Delayed Fluorescence Material as Host. Adv. Mater. 2015, 27, 4041-4047. [CrossRef]

20. Dai, X.L.; Zhang, Z.X.; Jin, Y.Z.; Niu, Y.; Cao, H.J.; Liang, X.Y.; Chen, L.W.; Wang, J.P.; Peng, X.G. Solution-Processed, High Performance Light-Emitting Diodes Based on Quantum Dots. Nature 2014, 515, 96-100. [CrossRef]

21. Jiang, C.; Zhong, Z.; Liu, B.; He, Z.; Zou, J.; Wang, L.; Wang, J.; Peng, J.B.; Cao, Y. Coffee-Ring-Free Quantum Dot Thin Film Using Inkjet Printing from a Mixed-Solvent System on Modified ZnO Transport Layer for Light-Emitting Devices. ACS Appl. Mater. Int. 2016, 8, 26162-26168. [CrossRef] [PubMed]

22. Jiang, C.; Liu, H.; Liu, B.; Zhong, Z.; Zou, J.; Wang, J.; Wang, L.; Peng, J.; Cao, Y. Improved performance of inverted quantum dots light emitting devices by introducing double hole transport layers. Org. Electron. 2016, 31, 82-89. [CrossRef]

23. Shirasaki, Y.; Supran, G.J.; Bawendi, M.G.; Bulović, V. Emergence of colloidal quantum-dot light-emitting technologies. Nat. Photonics 2013, 7, 13-23. [CrossRef]

24. Tan, Z.K.; Moghaddam, R.S.; Lai, M.L.; Docampo, P.; Higler, R.; Deschler, F.; Price, M.; Sadhanala, A.; Pazos, L.M.; Credgington, D.; et al. Bright light-emitting diodes based on organometal halide perovskite. Nat. Nanotechnol. 2014, 9, 687-692. [CrossRef] [PubMed]

25. Ji, H.; Shi, Z.; Sun, X.; Li, Y.; Li, S.; Lei, L.; Wu, D.; Xu, T.; Li, X.; Du, G. Vapor-Assisted Solution Approach for High-Quality Perovskite $\mathrm{CH}_{3} \mathrm{NH}_{3} \mathrm{PbBr}_{3}$ Thin Films for High-Performance Green Light-Emitting Diode Applications. ACS Appl. Mater. Int. 2017, 9, 42893-42904. [CrossRef]

26. Liu, B.; Wang, L.; Gu, H.; Sun, H.; Demir, H.V. Highly Efficient Green Light-Emitting Diodes from All-Inorganic Perovskite Nanocrystals Enabled by a New Electron Transport Layer. Adv. Opt. Mater. 2018, 5, 1800220. [CrossRef]

27. Wang, L.; Liu, B.; Zhao, X.; Demir, H.V.; Gu, H.; Sun, H. Solvent-Assisted Surface Engineering for High Performance All-Inorganic Perovskite Nanocrystals Light-Emitting Diodes. ACS Appl. Mater. Int. 2018, 10, 19828-19835. [CrossRef]

28. Chen, Z.; Nadal, B.; Mahler, B.; Aubin, H.; Dubertret, B. Quasi-2D Colloidal Semiconductor Nanoplatelets for Narrow Electroluminescence. Adv. Funct. Mater. 2014, 24, 295-302. [CrossRef]

29. Fan, F.; Kanjanaboos, P.; Saravanapavanantham, M.; Beauregard, E.; Ingram, G.; Yassitepe, E.; Adachi, M.M.; Voznyy, O.; Johnston, A.K.; Walters, G.; et al. Colloidal CdSe1-X SXNanoplatelets with Narrow and Continuously-Tunable Electroluminescence. Nano Lett. 2015, 15, 4611-4615. [CrossRef]

30. Liu, B.; Delikanli, S.; Gao, Y.; Gungor, K.; Demir, H.V. Nanocrystal light-emitting diodes based on type II nanoplatelets. Nano Energy 2018, 47, 115-122. [CrossRef]

31. Zou, M.Z.; Ma, Y.; Yuan, X.; Hu, J.; Liu, J.; Jin, Z. Flexible devices: from materials, architectures to applications. J. Semicond. 2018, 39, 011010. [CrossRef]

32. Cho, D.-H.; Kwon, O.E.; Park, Y.-S.; Yu, B.G.; Lee, J.; Moon, J.; Cho, H.; Lee, H.; Cho, N.-S. Flexible integrated OLED substrates prepared by printing and plating process. Org. Electron. 2017, 50, 170-176. [CrossRef]

33. Lian, L.; Dong, D.; Feng, D.X.; He, G.F. Low roughness silver nanowire flexible transparent electrode by low temperature solution-processing for organic light emitting diodes. Org. Electron. 2017, 49, 9-18. [CrossRef]

34. Hong, K.; Yu, H.K.; Lee, I.; Kim, S.; Kim, Y.; Kim, K.; Lee, J.-L. Flexible top-emitting organic light emitting diodes with a functional dielectric reflector on a metal foil substrate. RSC Adv. 2018, 8, 26156-26160. [CrossRef]

35. Najafabadi, E.; Knauer, K.A.; Haske, W.; Fuentes-Hernandez, C.; Kippelen, B. Highly efficient inverted top-emitting green phosphorescent organic light-emitting diodes on glass and flexible substrates. Appl. Phys. Lett. 2012, 101, 023304. [CrossRef] 
36. Wang, L.; Xu, M.; Lan, L.F.; Zou, J.H.; Tao, H.; Xu, H.; Li, M.; Luo, D.X.; Peng, J.B. Research progress of active matrix organic light emitting diode (AMOLED) displays driven by metal oxide thin film transistors (TFT). Sci. Sin. Chim. 2013, 43, 1383-1397. [CrossRef]

37. Xu, H.; Luo, D.X.; Li, M.; Xu, M.; Zou, J.H.; Tao, H.; Lan, L.F.; Wang, L.; Peng, J.B.; Cao, Y. A flexible AMOLED display on the PEN substrate driven by oxide thin-film transistors using anodized aluminium oxide as dielectric. J. Mater. Chem. C 2014, 2, 1255-1259. [CrossRef]

38. Wang, Y.X.; Liu, P.; Wang, H.H.; Zeng, B.Q.; Wang, J.H.; Chi, F. Flexible organic light-emitting devices with copper nanowire composite transparent conductive electrode. J. Mater. Sci. 2018, 54, 2343-2350. [CrossRef]

39. Shen, P.Y.; Li, X.M.; Cao, F.; Ding, X.W.; Yang, X.Y. Highly efficient, all-solution-processed, flexible white quantum dot light-emitting diodes. J. Mater. Chem. C 2018, 6, 9642-9648. [CrossRef]

40. Sun, Y.-K.; Yi, F.-S.; Bi, Y.-G.; Feng, J. Spontaneously formed random corrugations for efficient light extraction enhancement in flexible organic light-emitting devices. Org. Electron. 2019, 65, 91-95. [CrossRef]

41. Gustafsson, G.; Cao, Y.; Treacy, G.M.; Klavetter, F.; Colaneri, N.; Heeger, A.J. Flexible light-emitting diodes made from soluble conducting polymers. Nature 1992, 357, 477-479. [CrossRef]

42. Gu, G.; Burrows, P.E.; Venkatesh, S.; Forrest, S.R. Vacuum-deposited, nonpolymeric flexible organic light-emitting devices. Opt. Lett. 1997, 22, 172-174. [CrossRef] [PubMed]

43. Kim, S.; Kwon, H.-J.; Lee, S.; Shim, H.; Chun, Y.; Choi, W.; Kwack, J.; Han, D.; Song, M.; Kim, S.; et al. Low-power flexible organic light-emitting diode display device. Adv. Mater. 2011, 23, 3475. [CrossRef]

44. Wang, Z.B.; Helander, M.G.; Qiu, J.; Puzzo, D.P.; Greiner, M.T.; Hudson, Z.M.; Wang, S.; Liu, Z.W.; Lu, Z.H. Unlocking the full potential of organic light-emitting diodes on flexible plastic. Nature Photonics 2011, 5, 753-757. [CrossRef]

45. Available online: https://www.theinquirer.net/inquirer/news/3065513/display-maker-royole-shows-offworlds-first-flexible-smartphone (accessed on 22 February 2019).

46. Liu, B.; Li, X.; Tao, H.; Zou, J.; Xu, M.; Wang, L.; Peng, J.; Cao, Y. Manipulation of Exciton Distribution for High-Performance Fluorescent/Phosphorescent Hybrid White Organic Light-Emitting Diodes. J. Mater. Chem. C 2017, 5, 7668-7683. [CrossRef]

47. Luo, D.X.; Yang, Y.B.; Huang, L.; Liu, B.; Zhao, Y. High-performance hybrid white organic light-emitting diodes exploiting blue thermally activated delayed fluorescent dyes. Dyes Pigments 2017, 147, 83-89. [CrossRef]

48. Sasabe, H.; Kido, J. Development of High Performance OLEDs for General Lighting. J. Mater. Chem. C 2013, 1, 1699-1707. [CrossRef]

49. Wang, Q.; Ma, D. Management of Charges and Excitons for High-performance White Organic Light-emitting Diodes. Chem. Soc. Rev. 2010, 39, 2387-2398. [CrossRef]

50. Wu, Z.; Luo, J.J.; Sun, N.; Zhu, L.P.; Sun, H.D.; Yu, L.; Yang, D.Z.; Qiao, X.F.; Chen, J.S.; Yang, C.L.; et al. High Performance Hybrid White Organic Light-Emitting Diodes with Superior Efficiency/Color Rendering Index/Color Stability and Low Efficiency Roll-Off Based on a Blue Thermally Activated Delayed Fluorescent Emitter. Adv. Funct. Mater. 2016, 26, 3306-3313. [CrossRef]

51. Wu, Z.B.; Sun, N.; Zhu, L.P.; Sun, H.D.; Wang, J.X.; Yang, D.Z.; Qiao, X.F.; Chen, J.S.; Alshehri, S.; Ahamad, T.; et al. Achieving Extreme Utilization of Excitons by an Efficient Sandwich-Type Emissive Layer Architecture for Reduced Efficiency Roll-Off and Improved Operational Stability in Organic Light-Emitting Diodes. ACS Appl. Mater. Int. 2016, 8, 3150-3159. [CrossRef]

52. Zhu, L.P.; Chen, J.S.; Ma, D.G. Dopant effects on charge transport to enhance performance of phosphorescent white organic light emitting diodes. J. Appl. Phys. 2015, 118, 175503. [CrossRef]

53. Zhu, L.P.; Zhao, Y.B.; Zhang, H.M.; Chen, J.S.; Ma, D.G. Using an ultra-thin non-doped orange emission layer to realize high efficiency white organic light-emitting diodes with low efficiency roll-off. J. Appl. Phys. 2014, 115, 244512. [CrossRef]

54. Liu, B.; Zou, J.H.; Zhou, Z.W.; Wang, L.; Xu, M.; Tao, H.; Gao, D.Y.; Lan, L.Y.; Ning, H.L.; Peng, J.B. Efficient single-emitting layer hybrid white organic light-emitting diodes with low efficiency roll-off, stable color and extremely high luminance. J. Ind. Eng. Chem. 2015, 30, 85-91. [CrossRef]

55. Rao, M.V.M.; Su, Y.K.; Huang, T.S.; Chen, Y.C. White Organic Light Emitting Devices Based on Multiple Emissive Nanolayers. Nano-Micro Lett. 2010, 2, 242-246.

56. Zhang, L.; Li, X.-L.; Luo, D.; Xiao, P.; Xiao, W.; Song, Y.; Ang, Q.; Liu, B. Strategies to Achieve High-Performance White Organic Light-Emitting Diodes. Materials 2017, 10, 1378. [CrossRef] [PubMed] 
57. Kido, J.; Hongawa, K.; Okuyama, K.; Nagai, K. White Light-Emitting Organic Electroluminescent Devices Using the Poly (N-vinylcarbazole) Emitter Layer Doped with Three Fluorescent Dyes. Appl. Phys. Lett. 1994, 64, 815-817. [CrossRef]

58. Kido, J.; Kimura, M.; Nagai, K. Multilayer White Light-Emitting Organic Electroluminescent Device. Science 1995, 267, 1332-1334. [CrossRef] [PubMed]

59. Ou, Q.D.; Zhou, L.; Li, Y.Q.; Chen, S.; Chen, J.D.; Li, C.; Wang, Q.K.; Lee, S.T.; Tang, J.X. Extremely Efficient White Organic Light-Emitting Diodes for General Lighting. Adv. Funct. Mater. 2014, 24, 7249-7256. [CrossRef]

60. Duan, L.; Zhang, D.Q.; Wu, K.W.; Huang, X.Q.; Wang, L.D.; Qiu, Y. Controlling the Recombination Zone of White Organic Light-Emitting Diodes with Extremely Long Lifetimes. Adv. Funct. Mater. 2011, 21, 3540-3545. [CrossRef]

61. Liu, B.; Wang, L.; Xu, M.; Tao, H.; Zou, J.H.; Gao, D.Y.; Lan, L.F.; Ning, H.L.; Peng, J.B.; Cao, Y. Efficient Hybrid White Organic Light-emitting Diodes with Extremely Long Lifetime: the Effect of n-type Interlayer. Sci. Rep. 2014, 4, 7198. [CrossRef] [PubMed]

62. Guo, J.J.; Li, X.L.; Nie, H.; Luo, W.W.; Gan, S.F.; Hu, S.M.; Hu, R.R.; Qin, A.J.; Zhao, Z.J.; Su, S.J.; et al. Achieving High-Performance Nondoped OLEDs with Extremely Small Efficiency Roll-Off by Combining Aggregation-Induced Emission and Thermally Activated Delayed Fluorescence. Adv. Funct. Mater. 2017, 27, 1606458. [CrossRef]

63. Sun, N.; Zhao, Y.B.; Zhao, F.C.; Chen, Y.H.; Yang, D.Z.; Chen, J.S.; Ma, D.G. A white organic light-emitting diode with ultra-high color rendering index, high efficiency, and extremely low efficiency roll-off. Appl. Phys. Lett. 2014, 105, 013303. [CrossRef]

64. Jou, J.-H.; Wu, R.-Z.; Yu, H.-H.; Li, C.-J.; Jou, Y.-C.; Peng, S.-H.; Chen, Y.-L.; Chen, C.-T.; Shen, S.-M.; Joers, P.; et al. Artificial Dusk-Light Based on Organic Light Emitting Diodes. ACS Photonics 2014, 1, $27-31$. [CrossRef]

65. Liu, B.; Xu, M.; Wang, L.; Tao, H.; Su, Y.; Gao, D.; Lan, L.; Zou, J.; Peng, J. Very-High Color Rendering Index Hybrid White Organic Light-Emitting Diodes with Double Emitting Nanolayers. Nano-Micro Lett. 2014, 6 , 335-339. [CrossRef] [PubMed]

66. Liu, B.; Luo, D.; Gao, D.; Wang, X.; Xu, M.; Zou, J.; Ning, H.; Wang, L.; Peng, J.; Cao, Y. An ideal host-guest system to accomplish high-performance greenishyellow and hybrid white organic light-emitting diodes. Org. Electron. 2015, 27, 29-34. [CrossRef]

67. Jou, J.H.; Wu, M.H.; Shen, S.M.; Wang, H.C.; Chen, S.Z.; Chen, S.H.; Lin, C.R.; Hsieh, Y.L. Sunlight-Style Color-Temperature Tunable Organic Light-Emitting Diode. Appl. Phys. Lett. 2009, 95, 013307. [CrossRef]

68. Jou, J.-H.; Hsieh, C.-Y.; Tseng, J.-R.; Peng, S.-H.; Jou, Y.-C.; Hong, J.H.; Shen, S.-M.; Tang, M.-C.; Chen, P.-C.; Lin, C.-H. Candle Light-Style Organic Light-Emitting Diodes. Adv. Funct. Mater. 2013, 23, 2750-2757. [CrossRef]

69. Liu, B.; Nie, H.; Zhou, X.B.; Hu, S.B.; Luo, D.X.; Gao, D.Y.; Zou, J.H.; Xu, M.; Wang, L.; Zhao, Z.J.; et al. Manipulation of Charge and Exciton Distribution Based on Blue Aggregation-Induced Emission Fluorophors: A Novel Concept to Achieve High-Performance Hybrid White Organic Light-Emitting Diodes. Adv. Funct. Mater. 2016, 26, 776-783. [CrossRef]

70. Liu, B.; Xu, Z.P.; Zou, J.H.; Tao, H.; Xu, M.; Gao, D.Y.; Lan, L.F.; Wang, L.; Ning, H.L.; Peng, J.B. High-performance hybrid white organic light-emitting diodes employing p-type interlayers. J. Ind. Eng. Chem. 2015, 27, 240-244. [CrossRef]

71. Luo, D.X.; Yang, Y.F.; Xiao, Y.; Zhao, Y.; Yang, Y.B.; Liu, B.Q. Regulating Charge and Exciton Distribution in High-Performance Hybrid White Organic Light-Emitting Diodes with n-Type Interlayer Switch. Nano-Micro Lett. 2017, 9, 37. [CrossRef]

72. Pu, Y.J.; Chiba, T.; Ideta, K.; Takahashi, S.; Aizawa, N.; Hikichi, T.; Kido, J. Fabrication of Organic Light-Emitting Devices Comprising Stacked Light-Emitting Units by Solution-Based Processes. Adv. Mater. 2015, 27, 1327-1332. [CrossRef] [PubMed]

73. Liu, B.; Wang, L.; Gao, D.Y.; Xu, M.; Zhu, X.H.; Zou, J.H.; Lan, L.F.; Ning, H.L.; Peng, J.B.; Cao, Y. Harnessing charge and exciton distribution towards extremely high performance: the critical role of guests in single-emitting-layer white OLEDs. Mater. Horiz. 2015, 2, 536-544. [CrossRef] 
74. Zhao, Y.; Zhu, L.; Chen, J.; Ma, D. Improving Color Stability of Blue/Orange Complementary White OLEDs by Using Single-Host Double-Emissive Layer Structure: Comprehensive Experimental Investigation into the Device Working Mechanism. Org. Electron. 2012, 13, 1340-1348. [CrossRef]

75. Chen, Y.; Zhao, F.; Zhao, Y.; Chen, J.; Ma, D. Ultra-simple hybrid white organic light-emitting diodes with high efficiency and CRI trade-off: Fabrication and emission-mechanism analysis. Org. Electron. 2012, 13, 2807-2815. [CrossRef]

76. Schwartz, G.; Fehse, K.; Pfeiffer, M.; Walzer, K.; Leo, K. Highly efficient white organic light emitting diodes comprising an interlayer to separate fluorescent and phosphorescent regions. Appl. Phys. Lett. 2006, 89, 083509. [CrossRef]

77. Mikami, A.; Koshiyama, T.; Tsubokawa, T. High-Efficiency Color and White Organic Light-Emitting Devices Prepared on Flexible Plastic Substrates. Jpn. J. Appl. Phys. 2005, 44, 608-612. [CrossRef]

78. Liu, B.; Xu, M.; Tao, H.; Ying, L.; Zou, J.; Wu, H.; Peng, J. Highly Efficient Red Phosphorescent Organic Light-Emitting Diodes Based on Solution Processed Emissive Layer. J. Lumin. 2013, 142, 35-39. [CrossRef]

79. Xiang, C.; Koo, W.; So, F.; Sasabe, H.; Kido, J. A Systematic Study on Efficiency Enhancements in Phosphorescent Green, Red and Blue Microcavity Organic Light Emitting Devices. Light Sci. Appl. 2013, 2, e74. [CrossRef]

80. Xiao, P.; Dong, T.; Xie, J.; Luo, D.; Yuan, J.; Liu, B. Emergence of White Organic Light-Emitting Diodes Based on Thermally Activated Delayed Fluorescence. Appl. Sci. 2018, 8, 299. [CrossRef]

81. Nishimoto, T.; Yasuda, T.; Lee, S.Y.; Kondo, R.; Adachi, C. A Six-carbazole-decorated Cyclophosphazene as A Host with High Triplet Energy to Realize Efficient Delayed-Fluorescence OLEDs. Mater. Horiz. 2014, 1, 264-269. [CrossRef]

82. Zhang, Q.; Tsang, D.; Kuwabara, H.; Hatae, Y.; Li, B.; Takahashi, T.; Lee, S.Y.; Yasuda, T.; Adachi, C. Nearly 100\% Internal Quantum Efficiency in Undoped Electroluminescent Devices Employing Pure Organic Emitters. Adv. Mater. 2015, 27, 2096-2100. [CrossRef] [PubMed]

83. Adachi, C.; Baldo, M.A.; Thompson, M.E.; Forrest, S.R. Nearly 100\% Internal Phosphorescence Efficiency in an Organic Light-Emitting Device. J. Appl. Phys. 2001, 90, 5048-5051. [CrossRef]

84. Kanno, H.; Holmes, R.J.; Sun, Y.; Kena, S.; Forrest, S.R. White Stacked Electrophosphorescent Organic Light-Emitting Devices Employing $\mathrm{MoO}_{3}$ as a Charge-Generation Layer. Adv. Mater. 2006, 18, 339-342. [CrossRef]

85. Liu, B.; Wang, L.; Xu, M.; Tao, H.; Xia, X.; Zou, J.; Su, Y.; Gao, D.; Lan, L.; Peng, J. Simultaneous Achievement of Low Efficiency Roll-Off and Stable Color in Highly Efficient Single-Emitting-Layer Phosphorescent White Organic Light-Emitting Diodes. J. Mater. Chem. C 2014, 2, 5870-5877. [CrossRef]

86. Fleetham, T.; Ecton, J.; Wang, Z.; Bakken, N. Single-Doped White Organic Light-Emitting Device with an External Quantum Efficiency Over 20\%. Adv. Mater. 2013, 25, 2573-2576. [CrossRef] [PubMed]

87. Xu, L.; Tang, C.W.; Rothberg, L.J. High Efficiency Phosphorescent White Organic Light-Emitting Diodes with An Ultra-Thin Red and Green Co-Doped Layer and Dual Blue Emitting Layers. Org. Electron. 2016, 32, 54-58. [CrossRef]

88. Uoyama, H.; Goushi, K.; Shizu, K.; Nomura, H.; Adachi, C. Highly Efficient Organic Light-Emitting Diodes From Delayed Fluorescence. Nature 2012, 492, 234-238. [CrossRef]

89. Zhang, Q.S.; Li, B.; Huang, S.P.; Nomura, H.; Tanaka, H.; Adachi, C. Efficient blue organic light-emitting diodes employing thermally activated delayed fluorescence. Nat. Photonics 2014, 8, 326-332. [CrossRef]

90. Kim, B.S.; Lee, J.Y. Engineering of Mixed Host for High External Quantum Efficiency above 25\% in Green Thermally Activated Delayed Fluorescence Device. Adv. Funct. Mater. 2015, 24, 3970-3977. [CrossRef]

91. Cho, Y.J.; Yook, K.S.; Lee, J.Y. Cool and Warm Hybrid White Organic Light-Emitting Diode with Blue Delayed Fluorescent Emitter Both as Blue Emitter and Triplet Host. Sci. Rep. 2015, 5, 7859. [CrossRef]

92. Xiao, P.; Huang, J.; Yu, Y.; Yuan, J.; Luo, D.; Liu, B.; Liang, D. Recent Advances of Exciplex-Based White Organic Light-Emitting Diodes. Sci. Appl. 2018, 8, 1449. [CrossRef]

93. Xiang, H.-Y.; Li, Y.-Q.; Meng, S.-S.; Lee, C.-S.; Chen, L.-S.; Tang, J.-X. Extremely Efficient Transparent Flexible Organic Light-Emitting Diodes with Nanostructured Composite Electrodes. Adv. Opt. Mater. 2018, 6, 1800831. [CrossRef]

94. Mazzeo, M.; Mariano, F.; Genco, A.; Carallo, S.; Gigli, G. High efficiency ITO-free flexible white organic light-emitting diodes based on multi-cavity technology. Org. Electron. 2013, 14, 2840-2846. [CrossRef] 
95. Shi, H.Y.; Deng, L.L.; Chen, S.F.; Xu, Y.; Zhou, H.W.; Cheng, F.; Li, X.G.; Wang, L.H.; Huang, W. Flexible top-emitting warm-white organic light-emitting diodes with highly luminous performances and extremely stable chromaticity. Org. Electron. 2014, 15, 1465-1475. [CrossRef]

96. Chen, S.F.; Zhao, X.F.; Wu, Q.; Shi, H.Y.; Mei, Y.; Zhang, R.; Wang, L.H.; Huang, W. Efficient, color-stable flexible white top-emitting organic light-emitting diodes. Org. Electron. 2013, 14, 3037-3045. [CrossRef]

97. Xu, R.-P.; Li, Y.-Q.; Tang, J.-X. Recent advances in flexible organic light-emitting diodes. J. Mater. Chem. C 2016, 4, 9116-9142. [CrossRef]

98. Zhu, H.; Shen, Y.; Li, Y.Q.; Tang, J.X. Recent advances in flexible and wearable organic optoelectronic devices. J. Semicond. 2018, 39, 011011. [CrossRef]

99. Liu, Y.-F.; Feng, J.; Bi, Y.-G.; Yin, D.; Sun, H.-B. Recent Developments in Flexible Organic Light-Emitting Devices. Adv. Mater. Technol. 2019, 4, 1800371. [CrossRef]

100. Zhao, Y.B.; Chen, J.S.; Ma, D.G. Ultrathin Nondoped Emissive Layers for Efficient and Simple Monochrome and White Organic Light-Emitting Diodes. ACS Appl. Mater. Int. 2013, 5, 965-971. [CrossRef]

101. Yun, J.H. Ultrathin Metal films for Transparent Electrodes of Flexible Optoelectronic Devices. Adv. Funct. Mater. 2017, 27, 1606641. [CrossRef]

102. Zhang, D.D.; Duan, L.; Zhang, Y.G.; Cai, M.H.; Zhang, D.Q.; Qiu, Y. Highly efficient hybrid warm white organic light-emitting diodes using a blue thermally activated delayed fluorescence emitter: exploiting the external heavy-atom effect. Light Sci. Appl. 2015, 4, e232. [CrossRef]

103. Zhang, D.D.; Duan, L.; Li, Y.L.; Zhang, D.Q.; Qiu, Y. Highly efficient and color-stable hybrid warm white organic light-emitting diodes using a blue material with thermally activated delayed fluorescence. J. Mater. Chem. C 2014, 2, 8191-8197. [CrossRef]

104. Wei, P.C.; Zhang, D.D.; Cai, M.H.; Song, X.Z.; Wang, Z.Y.; Duan, L. Simplified Single-Emitting-Layer Hybrid White Organic Light-Emitting Diodes with High Efficiency, Low Efficiency Roll-Off, High Color Rendering Index and Superior Color. Org. Electron. 2017, 49, 242-248. [CrossRef]

105. Chang, C.C.; Chen, J.F.; Hwang, S.W.; Chen, C.H. Highly efficient white organic electroluminescent devices based on tandem architecture. Appl. Phys. Lett. 2005, 87, 253501. [CrossRef]

106. Hong, T.; Gao, D.; Liu, B.; Wang, L.; Zou, J.; Xu, M.; Peng, J. Enhancement of Tandem Organic Light-Emitting Diode Performance by Inserting An Ultra-Thin Ag Layer in Charge Generation Layer. Acta Phys. Sin. 2017, 1, 017302.

107. Liu, Y.; Chang, Q.H.; Huang, L. Transparent, flexible conducting graphene hybrid films with a subpercolating network of silver nanowires. J. Mater. Chem. C 2013, 1, 2970-2974. [CrossRef]

108. Gaynor, W.; Burkhard, G.F.; McGehee, M.D.; Peumans, P. Smooth nanowire/polymer composite transparent electrodes. Adv. Mater. 2011, 23, 2905-2910. [CrossRef]

109. Zhang, D.D.; Zhang, D.Q.; Duan, L. Exploiting p-Type Delayed Fluorescence in Hybrid White OLEDs: Breaking the Trade-off between High Device Efficiency and Long Lifetime. ACS Appl. Mater. Int. 2016, 8, 23197-23203. [CrossRef] [PubMed]

110. Zhang, T.; Zhao, B.; Chu, B.; Li, W.; Su, Z.; Yan, X.; Liu, C.; Wu, H.; Gao, Y.; Jin, F.; et al. Simple structured hybrid WOLEDs based on incomplete energy transfer mechanism: from blue exciplex to orange dopant. Sci. Rep. 2015, 5, 10234. [CrossRef] [PubMed]

111. Liu, B.; Xu, M.; Wang, L.; Su, Y.J.; Gao, D.Y.; Tao, H.; Lan, L.F.; Zou, J.H.; Peng, J.B. High-Performance Hybrid White Organic Light-Emitting Diodes Comprising Ultrathin Blue and Orange Emissive Layers. Appl. Phys. Express 2013, 6, 122101. [CrossRef]

112. Lim, J.T.; Lee, H.; Cho, H.; Kwon, B.-H.; Cho, N.S.; Lee, B.K.; Park, J.; Kim, J.; Han, J.-H.; Yang, J.-H.; et al. Flexion bonding transfer of multilayered graphene as a top electrode in transparent organic light-emitting diodes. Sci. Rep. 2015, 5, 17748. [CrossRef] [PubMed]

113. Han, T.-H.; Jeong, S.-H.; Lee, Y.; Seo, H.-K.; Kwon, S.-J.; Park, M.-H.; Lee, T.-W. Flexible transparent electrodes for organic light-emitting diodes. J. Inf. Display 2015, 16, 71-84. [CrossRef]

114. Knauer, K.A.; Najafabadi, E.; Haske, W.; Gaj, M.P.; Davis, K.C.; Fuentes-Hernandez, C.; Carrasco, U.; Kippelen, B. Stacked inverted top-emitting green electrophosphorescent organic light-emitting diodes on glass and flexible glass substrates. Org. Electron. 2013, 14, 2418-2423. [CrossRef]

115. Liu, Y.-F.; An, M.-H.; Bi, Y.-G.; Yin, D.; Feng, J.; Sun, H.-B. Flexible Efficient Top-Emitting Organic Light-Emitting Devices on a Silk Substrate. IEEE Photonics J. 2017, 9, 1-6. [CrossRef] 
116. Cherpak, V.; Stakhira, P.; Minaev, B.; Baryshnikov, G.; Stromylo, E.; Helzhynskyy, I.; Chapran, M.; Volyniuk, D.; Hotra, Z.; Dabuliene, A.; et al. Mixing of Phosphorescent and Exciplex Emission in Efficient Organic Electroluminescent Devices. ACS Appl. Mater. Int. 2015, 7, 1219-1225. [CrossRef] [PubMed]

117. Huang, J.-J.; Chen, Y.-P.; Lien, S.-Y.; Weng, K.-W.; Chao, C.-H. High mechanical and electrical reliability of bottom-gate microcrystalline silicon thin film transistors on polyimide substrate. Curr. Appl. Phys. 2011, 11, S266-S270. [CrossRef]

118. Yamaguchi, H.; Ueda, T.; Miura, K.; Saito, N.; Nakano, S.; Sakano, T.; Sugi, K.; Amemiya, I.; Hiramatsu, M.; Ishida, A. 74.2L: Late-News Paper: 11.7-inch Flexible AMOLED Display Driven by a-IGZO TFTs on Plastic Substrate. SID Symp. Dig. Tech. 2012, 43, 1002-1005. [CrossRef]

119. Ito, H.; Oka, W.; Goto, H.; Umeda, H. Plastic substrates for flexible displays. Jpn. J. Appl. Phys. 2006, 45, 4325-4329. [CrossRef]

120. Yang, X.Y.; Mutlugun, E.; Dang, C.; Dev, K.; Gao, Y.; Tan, S.T.; Sun, X.W.; Demir, H.V. Highly flexible, electrically driven, top-emitting, quantum dot light-emitting stickers. ACS Nano 2014, 8, 8224-8231. [CrossRef] [PubMed]

121. Liang, J.J.; Li, L.; Tong, K.; Ren, Z.; Hu, W.; Niu, X.F.; Chen, Y.S.; Pei, Q.B. Silver nanowire percolation network soldered with graphene oxide at room temperature and its application for fully stretchable polymer light-emitting diodes. ACS Nano 2014, 8, 1590-1600. [CrossRef] [PubMed]

122. Spechler, J.A.; Koh, T.-W.; Herb, J.T.; Rand, B.P.; Arnold, C.B. A Transparent, Smooth, Thermally Robust, Conductive Polyimide for Flexible Electronics. Adv. Funct. Mater. 2015, 25, 7428-7434. [CrossRef]

123. Yu, Z.B.; Zhang, Q.W.; Li, L.; Chen, Q.; Niu, X.F.; Liu, J.; Pei, Q.B. Highly flexible silver nanowire electrodes for shape-memory polymer light-emitting diodes. Adv. Mater. 2011, 23, 664-668. [CrossRef] [PubMed]

124. Nam, V.B.; Lee, D. Copper Nanowires and Their Applications for Flexible, Transparent Conducting Films: A Review. Nanomaterials 2016, 6, 47. [CrossRef] [PubMed]

125. Kim, E.; Cho, H.; Kim, K.; Koh, T.-W.; Chung, J.; Lee, J.; Park, Y.; Yoo, S. A facile route to efficient, low-cost flexible organic light-emitting diodes: utilizing the high refractive index and built-in scattering properties of industrial-grade PEN substrates. Adv. Mater. 2015, 27, 1624-1631. [CrossRef]

126. Wang, J.; Jiu, J.T.; Zhang, S.Y.; Sugahara, T.; Nagao, S.; Suganuma, K.; He, P. The comprehensive effects of visible light irradiation on silver nanowire transparent electrode. Nanotechnology 2018, 29, 435701. [CrossRef] [PubMed]

127. Gather, M.C.; Reineke, S. Recent Advances in Light Outcoupling from White Organic Light-Emitting Diodes. J. Photonics Energy 2015, 5, 057607. [CrossRef]

128. Lee, H.B.; Jin, W.-Y.; Ovhal, M.M.; Kumar, N.; Kang, J.-W. Flexible transparent conducting electrodes based on metal meshes for organic optoelectronic device applications: a review. J. Mater. Chem. C 2019. [CrossRef]

129. Chen, J.Y.; Yi, L.; Chen, J.; Ma, Y.W. Recent Progress in Silver and Copper Nanowire Flexible Transparent Conductors. Recent Pat. Mater. Sci. 2016, 9, 100-109. [CrossRef]

130. Madaria, A.R.; Kumar, A.; Zhou, C.W. Large scale, highly conductive and patterned transparent films of silver nanowires on arbitrary substrates and their application in touch screens. Nanotechnology 2011, 22, 245201. [CrossRef]

131. Xue, K.W.; Han, G.G.; Duan, Y.; Chen, P.; Yang, Y.Q.; Yang, D.; Duan, Y.H.; Wang, X.; Zhao, Y. Doping-free orange and white phosphorescent organic light-emitting diodes with ultra-simply structure and excellent color stability. Org. Electron. 2015, 18, 84-88. [CrossRef]

132. Jung, S.; Lee, S.; Song, M.; Kim, D.-G.; You, D.S.; Kim, J.-K.; Kim, C.S.; Kim, T.-M.; Kim, K.-H.; Kim, J.-J.; et al. Extremely Flexible Transparent Conducting Electrodes for Organic Devices. Adv. Energy Mater. 2014, 4, 1300474. [CrossRef]

133. Mayousse, C.; Celle, C.; Carella, A.; Simonato, J.-P. Synthesis and purification of long copper nanowires. Application to high performance flexible transparent electrodes with and without PEDOT: PSS. Nano Res. 2014, 7, 315-324. [CrossRef]

134. Cheng, Y.; Wang, S.L.; Wang, R.R.; Sun, J.; Gao, L. Copper nanowire based transparent conductive films with high stability and superior stretchability. J. Mater. Chem. C 2014, 2, 5309-5316. [CrossRef]

135. Kumar, D.V.R.; Woo, K.; Moon, J. Promising wet chemical strategies to synthesize Cu nanowires for emerging electronic applications. Nanoscale 2015, 7, 17195-17210. [CrossRef] [PubMed]

136. Lian, L.; Dong, D.; Wang, H.; He, G.F. Highly reliable copper nanowire electrode with enhanced transmittance and robustness for organic light emitting diodes. Org. Electron. 2019, 65, 70-76. [CrossRef] 
137. Shi, H.; Liu, C.C.; Jiang, Q.L.; Xu, J.K. Effective Approaches to Improve the Electrical Conductivity of PEDOT: PSS: A Review. Adv. Electron. Mater. 2015, 1, 1500017. [CrossRef]

138. Liu, G.H.; Zhou, X.; Chen, S.M. Very Bright and Efficient Microcavity Top-Emitting Quantum Dot Light-Emitting Diodes with Ag Electrodes. ACS Appl. Mater. Int. 2016, 8, 16768-16775. [CrossRef]

139. Kumar, G.; Li, Y.-D.; Biring, S.; Lin, Y.-N.; Liu, S.-W.; Chang, C.-H. Highly efficient ITO-free organic light-emitting diodes employing a roughened ultra-thin silver electrode. Org. Electron. 2017, 42, 52-58. [CrossRef]

140. Xue, K.W.; Sheng, R.; Duan, Y.; Chen, P.; Chen, B.Y.; Wang, X.; Duan, Y.H.; Zhao, Y. Efficient non-doped monochrome and white phosphorescent organic light-emitting diodes based on ultrathin emissive layers. Org. Electron. 2015, 26, 451-457. [CrossRef]

141. Wei, M.Z.; Wang, H.R.; Wang, J.T.; Chen, P.; Zhao, W.Z.; Chen, X.Y.; Guo, J.H.; Kang, B.N.; Duan, Y. Flexible transparent electrodes for organic light-emitting diodes simply fabricated with $\mathrm{AuCl}_{3}$-modied graphene. Org. Electron. 2018, 63, 71-77. [CrossRef]

142. Wang, S.L.; Yang, J.L.; Xu, T.; Dou, D.H.; Tang, Z.Y.; Gao, Z.X.; Chen, M.Y.; Guo, K.P.; Yu, J.S.; Plain, J.; et al. Highly efficient and foldable top-emission organic light-emitting diodes based on Ag-nanoparticles modified graphite electrode. Org. Electron. 2019, 64, 146-153. [CrossRef]

143. Zhang, Q.X.; Zhao, Y.H.; Jia, Z.H.; Qin, Z.F.; Chu, L.; Yang, J.P.; Zhang, J.; Huang, W.; Li, X.A. High Stable, Transparent and Conductive $\mathrm{ZnO} / \mathrm{Ag} / \mathrm{ZnO}$ Nanofilm Electrodes on Rigid/Flexible Substrates. Energies 2016, 9, 443. [CrossRef]

144. Yang, Z.Y.; Mao, Z.; Xie, Z.L.; Zhang, Y.; Liu, S.W.; Zhao, J.; Xu, J.R.; Chi, Z.G.; Aldred, M.P. Recent advances in organic thermally activated delayed fluorescence materials. Chem. Soc. Rev. 2017, 46, 915-1016. [CrossRef] [PubMed]

145. Lee, J.; Han, T.-H.; Park, M.-H.; Jung, D.Y.; Seo, J.; Seo, H.-K.; Cho, H.; Kim, E.; Chung, J.; Choi, S.-Y.; et al. Synergetic electrode architecture for efficient graphene-based flexible organic light-emitting diodes. Nat. Commun. 2016, 7, 11791. [CrossRef] [PubMed]

146. Luo, M.H.; Liu, Y.H.; Huang, W.B.; Qiao, W.; Zhou, Y.; Ye, Y.; Chen, L.-S. Towards Flexible Transparent Electrodes Based on Carbon and Metallic Materials. Micromachines 2017, 8, 12. [CrossRef]

147. Wang, D.R.; Zhang, Y.K.; Lu, X.; Ma, Z.J.; Xie, C.; Zheng, Z.J. Chemical formation of soft metal electrodes for flexible and wearable electronics. Chem. Soc. Rev. 2018, 47, 4611-4641. [CrossRef]

148. Morales-Masis, M.; Dauzou, F.; Jeangros, Q.; Dabirian, A.; Lifka, H.; Gierth, R.; Ruske, M.; Moet, D.; Hessler-Wyser, A.; Ballif, C. An Indium-Free Anode for Large-Area Flexible OLEDs: Defect-Free Transparent Conductive Zinc Tin Oxide. Adv. Funct. Mater. 2016, 26, 384-392. [CrossRef]

149. Khan, A.; Lee, S.; Jang, T.; Xiong, Z.; Zhang, C.P.; Tang, J.Y.; Guo, L.J.; Li, W.-D. High-Performance Flexible Transparent Electrode with an Embedded Metal Mesh Fabricated by Cost-Effective Solution Process. Small 2016, 12, 3021-3030. [CrossRef] [PubMed]

150. Chen, Y.H.; Chen, J.S.; Ma, D.G.; Yan, D.H.; Wang, L.X.; Zhu, F.R. High Power Efficiency Tandem Organic Light-Emitting Diodes Based on Bulk Heterojunction Organic Bipolar Charge Generatio Layer. Appl. Phys. Lett. 2011, 98, 243309. [CrossRef]

151. Zhou, J.; Zou, J.; Dai, C.; Zhang, Y.; Luo, X.; Liu, B. High-Efficiency and High-Luminance Three-Color White Organic Light-Emitting Diodes with Low Efficiency Roll-Off. ECS J. Solid State Sci. Technol. 2018, 7, R99-R103. [CrossRef]

152. Xiao, P.; Huang, J.; Yu, Y.; Liu, B. Recent Developments in Tandem White Organic Light-Emitting Diodes. Molecules 2019, 24, 151. [CrossRef] [PubMed]

153. Poloek, A.; Chen, C.-T.; Chen, C.-T. High performance hybrid white and multi-colour electroluminescence from a new host material for a heteroleptic naphthyridinolate platinum complex dopant. J. Mater. Chem. C 2014, 2, 1376-1380. [CrossRef]

154. Liao, L.S.; Klubek, K.P. Power Efficiency Improvement in A Tandem Organic Light-Emitting Diode. Appl. Phys. Lett. 2008, 92, 223311. [CrossRef]

155. Schwartz, G.; Reineke, S.; Rosenow, T.C.; Walzer, K.; Leo, K. Triplet Harvesting in Hybrid White Organic Light-Emitting Diodes. Adv. Funct. Mater. 2009, 19, 1319-1333. [CrossRef]

156. Liu, B.; Xu, M.; Wang, L.; Tao, H.; Su, Y.; Gao, D.; Zou, J.; Lan, L.; Peng, J. Comprehensive Study on the Electron Transport Layer in Blue Flourescent Organic Light-Emitting Diodes. ECS J. Solid State Sci. Technol. 2015, 2, R258-R261. [CrossRef] 
157. Du, X.; Tao, S.; Huang, Y.; Yang, X.; Ding, X.; Zhang, X. Efficient Fluorescence/Phosphorescence White Organic Light-Emitting Diodes With Ultra High Color Stability and Mild Efficiency Roll-Off. Appl. Phys. Lett. 2015, 107, 183304. [CrossRef]

158. Luo, D.; Li, X.-L.; Zhao, Y.; Gao, Y.; Liu, B. High-Performance Blue Molecular Emitter-Free and Doping-Free Hybrid White Organic Light-Emitting Diodes: an Alternative Concept to Manipulate Charges and Excitons Based on Exciplex and Electroplex Emission. ACS Photonics 2017, 4, 1566-1575. [CrossRef]

159. Rosenow, T.C.; Furno, M.; Reineke, S.; Olthof, S.; Lussem, B.; Leo, K. Highly efficient white organic light-emitting diodes based on fluorescent blue emitters. J. Appl. Phys. 2010, 108, 113113. [CrossRef]

160. Schwab, T.; Schubert, S.; Hofmann, S.; Frobel, M.; Fuchs, C.; Thomschke, M.; Muller-Meskamp, L.; Leo, K.; Gather, M.C. Highly Efficient and Color Stable Inverted White Top-emitting OLEDs with Ultra-thin Wetting Layer Top Electrodes. Adv. Opt. Mater. 2013, 1, 707-713. [CrossRef]

161. Liu, B.; Luo, D.X.; Zou, J.H.; Gao, D.Y.; Ning, H.L.; Wang, L.; Peng, J.B.; Cao, Y. A host-guest system comprising high guest concentration to achieve simplified and high-performance hybrid white organic light-emitting diodes. J. Mater. Chem. C 2015, 3, 6359-6366. [CrossRef]

162. Luo, D.X.; Xiao, Y.; Hao, M.M.; Zhao, Y.; Yang, Y.B.; Gao, Y.; Liu, B. Doping-free white organic light-emitting diodes without blue molecular emitter: An unexplored approach to achieve high performance via exciplex emission. Appl. Phys. Lett. 2017, 110, 061105. [CrossRef]

163. Luo, D.; Chen, Q.; Gao, Y.; Zhang, M.; Liu, B. Extremely Simplified, High-Performance and Doping-Free White Organic Light-Emitting Diodes Based on Single Thermally Activated Delayed Fluorescent Emitter. ACS Energy Lett. 2018, 3, 1531-1538. [CrossRef]

164. Kim, B.S.; Yook, K.S.; Lee, J.Y. Above 20\% External Quantum Efficiency in Novel Hybrid White Organic Light-Emitting Diodes Having Green Thermally Activated Delayed Fluorescent Emitter. Sci. Rep. 2014, 4, 6019. [CrossRef] [PubMed]

165. Sun, Y.R.; Giebink, N.C.; Kanno, H.; Ma, B.W.; Thompson, M.E.; Forrest, S.R. Management of Singlet and Triplet Excitons for Efficient White Organic Light-Emitting Devices. Nature 2006, 440, 908-912. [CrossRef] [PubMed]

166. Chen, B.; Liu, B.; Zeng, J.; Nie, H.; Xiong, Y.; Zou, J.; Ning, H.; Wang, Z.; Zhao, Z.; Tang, B.Z. Efficient Bipolar Blue AIEgens for High-Performance Nondoped Blue OLEDs and Hybrid White OLEDs. Adv. Func. Mater. 2018, 28, 1803369. [CrossRef]

167. Liu, B.; Xu, M.; Wang, L.; Zou, J.H.; Tao, H.; Su, Y.J.; Gao, D.Y.; Ning, H.L.; Lan, L.F.; Peng, J.B. Regulating charges and excitons in simplified hybrid white organic light-emitting diodes: The key role of concentration in single dopant host-guest systems. Org. Electron. 2014, 15, 2616-2623. [CrossRef]

168. Zhao, F.C.; Zhang, Z.Q.; Liu, Y.P.; Dai, Y.F.; Chen, J.S.; Ma, D. A Hybrid White Organic Light-Emitting Diode with Stable Color and Reduced Efficiency Roll-Off by Using a Bipolar Charge Carrier Switch. Org. Electron. 2012, 13, 1049-1055. [CrossRef]

169. Chen, Y.-H.; Ma, D.-G.; Sun, H.-D.; Chen, J.-S.; Guo, Q.-X.; Wang, Q.; Zhao, Y.-B. Organic Semiconductor Heterojunctions: Electrode-Independent Charge Injectors for High-Performance Organic Light-Emitting Diodes. Light Sci. Appl. 2016, 5, e16042. [CrossRef]

170. Li, X.L.; Xie, G.Z.; Liu, M.; Chen, D.C.; Cai, X.Y.; Peng, J.B.; Cao, Y.; Su, S.J. High-Efficiency WOLEDs with High Color-Rendering Index based on a Chromaticity-Adjustable Yellow Thermally Activated Delayed Fluorescence Emitter. Adv. Mater. 2016, 28, 4614-4619. [CrossRef]

171. Wang, Q.; Ding, J.; Ma, D.; Cheng, Y.; Wang, L.; Jing, X.; Wang, F. Harvesting Excitons Via Two Parallel Channels for Efficient White Organic LEDs with Nearly 100\% Internal Quantum Efficiency: Fabrication and Emission-Mechanism Analysis. Adv. Funct. Mater. 2009, 19, 84-95. [CrossRef]

172. Huang, W.Y.; Chen, Z.W.; You, H.W.; Fan, F.C.; Chen, H.F.; Wong, K.T. Efficient Carrier and Exciton-Confining Device Structure that Enhances Blue PhOLED Efficiency and Reduces Efficiency Roll-Off. Org. Electron. 2011, 12, 575-581. [CrossRef]

173. Ouyang, X.H.; Li, X.L.; Bai, Y.Q.; Mi, D.B.; Ge, Z.Y.; Su, S.J. Highly-efficient hybrid white organic light-emitting diodes based on a high radiative exciton ratio deepblue emitter with improved concentration of phosphorescent dopant. RSC Adv. 2015, 5, 32298-32306. [CrossRef]

174. Fleetham, T.; Huang, L.; Li, J. Tetradentate Platinum Complexes for Efficient and Stable Excimer-Based White OLEDs. Adv. Funct. Mater. 2015, 24, 6066-6073. [CrossRef] 
175. Chen, P.; Xie, W.F.; Li, K.; Guan, T.; Duan, Y.; Zhao, Y.; Liu, S.Y.; Ma, C.S.; Zhang, L.Y.; Li, B. White organic light-emitting devices with a bipolar transport layer between blue fluorescent and orange phosphorescent emitting layers. Appl. Phys. Lett. 2007, 91, 023505. [CrossRef]

176. Liu, B.; Xu, M.; Tao, H.; Su, Y.J.; Gao, D.Y.; Zou, J.H.; Lan, L.F.; Peng, J.B. The effect of spacer in hybrid white organic light emitting diodes. Chinese Sci. Bull. 2014, 59, 3090-3097. [CrossRef]

177. Lee, S.; Kim, K.-H.; Limbach, D.; Park, Y.-S.; Kim, J.-J. Low Roll-Off and High Efficiency Orange Organic Light Emitting Diodes with Controlled Co-Doping of Green and Red Phosphorescent Dopants in an Exciplex Forming Co-Host. Adv. Funct. Mater. 2013, 23, 4105-4110. [CrossRef]

178. Zhu, L.; Wu, Z.; Chen, J.; Ma, D. Reduced Efficiency Roll-Off in All-Phosphores-cent White Organic Light-Emitting Diodes with an External Quantum Efficiency of Over 20\%. J. Mater. Chem. C 2015, 3, 3304-3310. [CrossRef]

179. Sun, N.; Wang, Q.; Zhao, Y.B.; Yang, D.Z.; Zhao, F.C.; Chen, J.S.; Ma, D.G. A hybrid white organic light-emitting diode with above $20 \%$ external quantum efficiency and extremely low efficiency roll-off. J. Mater. Chem. C 2014, 2, 7494-7504. [CrossRef]

180. Wu, Z.; Yu, L.; Zhao, F.; Qiao, X.; Chen, J.; Ni, F.; Yang, C.; Ahamad, T.; Alshehri, S.M.; Ma, D. Precise Exciton Allocation for Highly Effcient White Organic Light-Emitting Diodes with Low Effciency Roll-Off Based on Blue Thermally Activated Delayed Fluorescent Exciplex Emission. Adv. Opt. Mater. 2017, 5, 1700415. [CrossRef]

181. Liu, B.; Tao, H.; Su, Y.J.; Gao, D.Y.; Lan, L.F.; Zou, J.H.; Peng, J.B. Color-stable, reduced efficiency roll-off hybrid white organic light emitting diodes with ultra high brightness. Chinese Phys. B 2013, 22, 077303. [CrossRef]

182. Liu, B.; Tao, H.; Wang, L.; Gao, D.Y.; Liu, W.C.; Zou, J.H.; Xu, M.; Ning, H.L.; Peng, J.B.; Cao, Y. High-performance doping-free hybrid white organic light-emitting diodes: The exploitation of ultrathin emitting nanolayers ( $<1 \mathrm{~nm}$ ). Nano Energy 2016, 26, 26-36. [CrossRef]

183. Schwartz, G.; Ke, T.-H.; Wu, C.-C.; Walzer, K.; Leo, K. Balanced ambipolar charge carrier mobility in mixed layers for application in hybrid white organic light-emitting diodes. Appl. Phys. Lett. 2008, 93, 073304. [CrossRef]

184. Schwartz, G.; Reineke, S.; Walzer, K.; Leo, K. Reduced efficiency roll-off in high-efficiency hybrid white organic light-emitting diodes. Appl. Phys. Lett. 2008, 92, 053311. [CrossRef]

185. Kanno, H.; Giebink, N.C.; Sun, Y.; Forrest, S.R. Stacked white organic light-emitting devices based on a combination of fluorescent and phosphorescent emitters. Appl. Phys. Lett. 2006, 89, 023503. [CrossRef]

186. Schwartz, G.; Pfeiffer, M.; Reineke, S.; Walzer, K.; Leo, K. Harvesting Triplet Excitons from Fluorescent Blue Emitters in White Organic Light-Emitting Diodes. Adv. Mater. 2007, 19, 3672-3676. [CrossRef]

187. Ye, J.; Zheng, C.-J.; Ou, X.-M.; Zhang, X.-H.; Fung, M.-K.; Lee, C.-S. Management of Singlet and Triplet Excitons in a Single Emission Layer: A Simple Approach for a High-Efficiency Fluorescence/Phosphorescence Hybrid White Organic Light-Emitting Device. Adv. Mater. 2012, 24, 3410-3414. [CrossRef] [PubMed]

188. Liu, B.; Xu, M.; Wang, L.; Yan, X.; Tao, H.; Su, Y.; Gao, D.; Lan, L.; Zou, J.; Peng, J. Investigation and Optimization of Each Organic Layer: A Simple But Effective Approach Towards Achieving High-Efficiency Hybrid White Organic Light-Emitting Diodes. Org. Electron. 2014, 15, 926-936. [CrossRef]

189. Liu, B.; Zou, J.H.; Su, Y.J.; Gao, D.Y.; Lan, L.F.; Tao, H.; Peng, J.B. Hybrid white organic light emitting diodes with low efficiency roll-off, stable color and extreme brightness. J. Lumin. 2014, 151, 161-164. [CrossRef]

190. Li, X.L.; Ouyang, X.H.; Liu, M.; Ge, Z.Y.; Peng, J.B.; Cao, Y.; Su, S.J. Highly efficient single-and multi-emission-layer fluorescent/phosphorescent hybrid white organic light-emitting diodes with $\sim 20 \%$ external quantum efficiency. J. Mater. Chem. C 2015, 3, 9233-9239. [CrossRef]

191. Liu, B.; Wang, L.; Gao, D.Y.; Zou, J.H.; Ning, H.L.; Peng, J.B.; Cao, Y. Extremely high-efficiency and ultrasimplified hybrid white organic light-emitting diodes exploiting double multifunctional blue emitting layers. Light Sci. Appl. 2016, 5, e16137. [CrossRef]

192. Reineke, S.; Lindner, F.; Schwartz, G.; Seidler, N.; Walzer, K.; Lüssem, B.; Leo, K. White organic light-emitting diodes with fluorescent tube efficiency. Nature 2009, 459, 234. [CrossRef] [PubMed]

193. Wu, Z.; Qi, W.; Ling, Y.; Chen, J.; Qiao, X.; Ahamad, T.; Alshehri, S.M.; Yang, C.; Ma, D. Managing excitons and charges for high-performance fluorescent white organic light-emitting diodes. ACS Appl. Mater. Int. 2016, 8, 28780-28788. [CrossRef] [PubMed] 
194. Song, H.-J.; Han, J.; Lee, G.; Sohn, J.; Kwon, Y.; Choi, M.; Lee, C. Enhanced light out-coupling in OLED employing thermal-assisted, self-aggregated silver nano particles. Org. Electron. 2018, 52, 230-236. [CrossRef]

195. Saxena, K.; Jain, V.K.; Mehta, D.S. A review on the light extraction techniques in organic electroluminescent devices. Opt. Mater. 2009, 32, 221-233. [CrossRef]

196. Bi, Y.-G.; Feng, J.; Liu, Y.-S.; Li, Y.-F.; Chen, Y.; Zhang, X.-L.; Han, X.-C.; Sun, H.-B. Surface plasmon-polariton mediated red emission from organic light-emitting devices based on metallic electrodes integrated with dual-periodic corrugation. Sci. Rep. 2014, 4, 7108. [CrossRef] [PubMed]

197. Sun, H.; Chen, Y.H.; Chen, J.S.; Ma, D. Interconnectors in Tandem Organic Light Emitting Diodes and Their Influence on Device Performance. IEEE J. Sel. Top. Quantum Electron. 2015, 22, 154-163. [CrossRef]

198. Koo, W.H.; Youn, W.; Zhu, P.F.; Li, X.-H.; Tansu, N.; So, F. Light Extraction of Organic Light Emitting Diodes by Defective Hexagonal-Close-Packed Array. Adv. Funct. Mater. 2012, 22, 3454-3459. [CrossRef]

199. Goushi, K.; Adachi, C. Efficient Organic Light-Emitting Diodes Through Up-Conversion from Triplet to Singlet Excited States of Exciplexes. Appl. Phys. Lett. 2012, 101, 3174-3178. [CrossRef]

200. Moon, J.; Kim, E.; Park, S.K.; Lee, K.; Shin, J.-W.; Cho, D.-H.; Lee, J.; Joo, C.W.; Cho, N.S.; Han, J.-H.; et al. Organic wrinkles for energy efficient organic light emitting diodes. Org. Electron. 2015, 26, 273-278. [CrossRef]

201. Yook, K.S.; Jeon, S.O.; Min, S.Y. Highly Efficient p-i-n and Tandem Organic Light-Emitting Devices Using an Air-Stable and Low-Temperature-Evaporable Metal Azide as an n-Dopant. Adv. Funct. Mater. 2010, 20, 1797-1802. [CrossRef]

202. Chen, Y.H.; Chen, J.S.; Ma, D.G.; Yan, D.H.; Wang, L.X.; Chen, Y. Effect of Organic Bulk Heterojunction as Charge Generation Layer on The Performance of Tandem Organic Light-Emitting Diodes. J. Appl. Phys. 2011, 110, 979. [CrossRef]

203. Cho, H.; Kim, E.; Moon, J.; Joo, C.W.; Kim, E.; Park, S.K.; Lee, J.; Yu, B.-G.; Lee, J.-I.; Yoo, S.; et al. Organic wrinkles embedded in high-index medium as planar internal scattering structures for organic light-emitting diodes. Org. Electron. 2017, 46, 139-144. [CrossRef]

204. Nakamura, T.; Tsutsumi, N.; Juni, N.; Fujii, H. Thin-film waveguiding mode light extraction in organic electroluminescent device using high refractive index substrate. J. Appl. Phys. 2005, 97, 054505. [CrossRef]

205. Lee, K.M.; Fardel, R.; Zhao, L.F.; Arnold, C.B.; Rand, B.P. Enhanced outcoupling in flexible organic light-emitting diodes on scattering polyimide substrates. Org. Electron. 2017, 51, 471-476. [CrossRef]

206. Ou, Q.-D.; Xu, L.-H.; Zhang, W.-Y.; Li, Y.-Q.; Zhang, Y.-B.; Zhao, X.-D.; Chen, J.-D.; Tang, J.-X. Light outcoupling enhanced flexible organic light-emitting diodes. Opt. Express 2016, 24, A674-A681. [CrossRef] [PubMed]

207. Kinner, L.; Nau, S.; Popovic, K.; Sax, S.; Burgués-Ceballos, I.; Hermerschmidt, F.; Lange, A.; Boeffel, C.; Choulis, S.A.; List-Kratochvil, E.J.W. Inkjet-printed embedded Ag-PEDOT: PSS electrodes with improved light out coupling effects for highly efficient ITO-free blue polymer light emitting diodes. Appl. Phys. Lett. 2017, 110, 101107. [CrossRef]

208. Liu, B.; Xu, M.; Wang, L.; Tao, H.; Su, Y.J.; Gao, D.Y.; Lan, L.F.; Zou, J.H.; Peng, J.B. Simplified hybrid white organic light-emitting diodes with efficiency/efficiency roll-off/color rendering index/color-stability trade-off. Phys. Status Solidi RRL 2014, 8, 719-723. [CrossRef]

209. Mai, R.S.; Wu, X.Y.; Jiang, Y.; Meng, Y.Y.; Liu, B.Q.; Hu, X.W.; Roncali, J.; Zhou, G.F.; Liu, J.-M.; Kempa, K.; et al. An efficient multi-functional material based on polyether-substituted indolocarbazole for perovskite solar cells and solution-processed non-doped OLEDs. J. Mater. Chem. A 2019, 7, 1539-1547. [CrossRef]

210. Liu, B.; Nie, H.; Lin, G.; Hu, S.; Gao, D.; Zou, J.; Xu, M.; Wang, L.; Zhao, Z.; Ning, H.; et al. High-Performance Doping-Free Hybrid White OLEDs Based on Blue Aggregation-Induced Emission Luminogens. ACS Appl. Mater. Int. 2017, 9, 34162-34171. [CrossRef] [PubMed]

211. Shen, S.M.; Lin, C.R.; Wang, Y.S.; Chou, Y.C.; Chen, S.Z.; Jou, J.H. Efficient Very-High Color Rendering index Organic Light-Emitting Diode. Org. Electron. 2011, 12, 865-868.

212. Yook, K.S.; Jeon, S.O.; Joo, C.W.; Lee, J.Y. Color stability and suppressed efficiency roll-off in white organic light-emitting diodes through management of interlayer and host properties. J. Ind. Eng. Chem. 2009, 15, 420-422. [CrossRef]

213. Su, S.-J.; Gonmori, E.; Sasabe, H.; Kido, J. Highly efficient organic blue- and white-light-emitting devices having a carrier- and exciton-confining structure for reduced efficiency roll-off. Adv. Mater. 2008, 20, 4189-4194. [CrossRef] 
214. Sun, N.; Wang, Q.; Zhao, Y.B.; Chen, Y.H.; Yang, D.Z.; Zhao, F.C.; Chen, J.S.; Ma, D.G. High-Performance Hybrid White Organic Light-Emitting Devices without Interlayer between Fluorescent and Phosphorescent Emissive Regions. Adv. Mater. 2014, 26, 1617-1621. [CrossRef] [PubMed]

215. Zhang, M.; Wang, K.; Zheng, C.-J.; Liu, W.; Lin, H.; Tao, S.-L.; Zhang, X.-H. Efficient, color-stable and high color-rendering-index white organic light-emitting diodes employing full thermally activated delayed fluorescence system. Org. Electron. 2017, 50, 466-472. [CrossRef]

216. Nishide, J.-I.; Nakanotani, H.; Hiraga, Y.; Adachi, C. High-efficiency white organic light-emitting diodes using thermally activated delayed fluorescence. Appl. Phys. Lett. 2014, 104, 233304. [CrossRef]

217. Liu, X.-K.; Zhan, C.; Jian, Q.; Wen-Jun, Z.; Bo, W.; Hoi Lam, T.; Zhu, F.; Zhang, X.-H.; Lee, C.-S. Organic light-emitting devices: remanagement of singlet and triplet excitons in single-emissive-layer hybrid white organic light-emitting devices using thermally activated delayed fluorescent blue exciplex. Adv. Mater. 2015, 27, 7079-7085. [CrossRef] [PubMed]

218. Jou, J.-H.; Wang, C.-P.; Wu, M.-H.; Lin, H.-W.; Pan, H.C.; Liu, B.-H. High-efficiency flexible white organic light-emitting diodes. J. Mater. Chem. 2010, 20, 6626-6629. [CrossRef]

219. Wu, J.B.; Agrawal, M.; Becerril, H.A.; Bao, Z.A.; Liu, Z.F.; Chen, Y.S.; Peumans, P. Organic light-emitting diodes on solution processed graphene transparent electrodes. ACS Nano 2010, 4, 43-48. [CrossRef]

220. Sun, T.; Wang, Z.L.; Shi, Z.J.; Ran, G.Z.; Xu, W.J.; Wang, Z.Y.; Li, Y.Z.; Dai, L.; Qin, G.G. Multilayered graphene used as anode of organic light emitting devices. Appl. Phys. Lett. 2010, 96, 133301. [CrossRef]

221. Han, T.-H.; Lee, Y.; Choi, M.-R.; Woo, S.-H.; Bae, S.-H.; Hong, B.H.; Ahn, J.-H.; Lee, T.-W. Extremely efficient flexible organic light-emitting diodes with modified graphene anode. Nat. Photonics 2012, 6, 105-110. [CrossRef]

222. Ji, W.Y.; Zhao, J.L.; Sun, Z.C.; Xie, W.F. High-color-rendering flexible top-emitting warm-white organic light emitting diode with a transparent multilayer cathode. Org. Electron. 2011, 12, 1137-1141. [CrossRef]

223. Ji, W.Y.; Zhang, L.T.; Xu, K.; Xie, W.F.; Zhang, H.Z.; Liu, G.Q.; Yao, J.B. Semitransparent white organic light-emitting devices with symmetrical electrode structure. Org. Electron. 2011, 12, 2192-2197. [CrossRef]

224. Li, N.; Oida, S.; Tulevski, G.S.; Han, S.-J.; Hannon, J.B.; Sadana, D.K.; Chen, T.-C. Efficient and bright organic light-emitting diodes on single-layer graphene electrodes. Nat. Commun. 2013, 4, 2294. [CrossRef] [PubMed]

225. Liu, B.; Wang, L.; Xu, M.; Tao, H.; Gao, D.; Zou, J.; Lan, L.; Ning, H.; Peng, J.; Cao, Y. Extremely Stable-color Flexible White Organic Light-emitting Diodes with Efficiency Exceeding $100 \mathrm{~lm} \mathrm{~W}^{-1}$. J. Mater. Chem. C 2014, 2, 9836-9841. [CrossRef]

226. Zhou, L.; Xiang, H.-Y.; Shen, S.; Li, Y.-Q.; Chen, J.-D.; Xie, H.-J.; Goldthorpe, I.A.; Chen, L.-S.; Lee, S.-T.; Tang, J.-X. High-performance flexible organic light-emitting diodes using embedded silver network transparent electrodes. ACS Nano 2014, 8, 12796-12805. [CrossRef] [PubMed]

227. Xu, L.-H.; Ou, Q.-D.; Li, Y.-Q.; Zhang, Y.-B.; Zhao, X.-D.; Xiang, H.-Y.; Chen, J.-D.; Zhou, L.; Lee, S.-T.; Tang, J.-X. Microcavity-Free Broadband Light Outcoupling Enhancement in Flexible Organic Light-Emitting Diodes with Nanostructured Transparent Metal-Dielectric Composite Electrodes. ACS Nano 2016, 10, 1625-1632. [CrossRef] [PubMed]

228. Koo, J.-R.; Lee, S.J.; Lee, H.W.; Lee, D.H.; Yang, H.J.; Kim, W.Y.; Kim, Y.K. Flexible bottom-emitting white organic light-emitting diodes with semitransparent Ni/Ag/Ni anode. Opt. Express 2013, 21, 11086-11094. [CrossRef]

229. Chen, S.F.; Zhang, Q.; Shang, W.J.; Liu, L.H.; Yu, H.T.; Zhang, S.; Deng, L.L.; Wang, M.; Wang, M.H.; $\mathrm{Li}, \mathrm{X}$;; et al. Interfacial engineering of graphene for highly efficient blue and white organic light-emitting devices. Sci. Rep. 2018, 8, 8155. [CrossRef]

230. Zhao, B.; Zhang, T.; Chu, B.; Li, W.; Su, Z.; Luo, Y.; Li, R.; Yan, X.; Jin, F.; Gao, Y.; et al. Highly efficient tandem full exciplex orange and warm white OLEDs based on thermally activated delayed fluorescence mechanism. Org. Electron. 2015, 17, 15-21. [CrossRef]

231. Rajamalli, P.; Senthilkumar, N.; Gandeepan, P.; Huang, P.-Y.; Huang, M.-J.; Yang, C.-Y.; Chiu, M.-J.; Chu, L.-K.; Lin, H.-W.; Cheng, C.-H. A New Molecular Design Based on Thermally Activated Delayed Fluorescence for Highly Efficient Organic Light Emitting Diodes. J. Am. Chem. Soc. 2016, 138, 628-634. [CrossRef]

232. Liu, B.; Wang, L.; Tao, H.; Xu, M.; Zou, J.; Ning, H.; Peng, J.; Cao, Y. Doping-Free Tandem White Organic Light-Emitting Diodes. Sci. Bull. 2017, 62, 1193-1200. [CrossRef]

233. Yoshihiro, O. Color rendering and luminous efficacy of white LED spectra. Proc. SPIE 2004, 88, 5530. 
234. Preinfalk, J.B.; Eiselt, T.; Wehlus, T.; Rohnacher, V.; Hanemann, T.; Gomard, G.; Lemmer, U. Large-Area Screen-Printed Internal Extraction Layers for Organic Light-Emitting Diodes. ACS Photonics 2017, 4, 928-933. [CrossRef]

235. Koh, T.-W.; Spechler, J.A.; Lee, K.M.; Arnold, C.B.; Rand, B.P. Enhanced Outcoupling in Organic Light-Emitting Diodes via a High-Index Contrast Scattering Layer. ACS Photonics 2015, 2, 1366-1372. [CrossRef]

236. Krotkus, S.; Kasemann, D.; Lenk, S.; Leo, K.; Reineke, S. Adjustable White-Light Emission From a Photo-Structured Micro-OLED Array. Light Sci. Appl. 2016, 5, e16121. [CrossRef] [PubMed]

237. Zhao, B.; Zhang, T.Y.; Li, W.L.; Su, Z.S.; Chu, B.; Yan, X.W.; Jin, F.M.; Gao, Y.; Wu, H. Organic Electronics Highly efficient and color stable single-emitting-layer fluorescent WOLEDs with delayed fluorescent host. Org. Electron. 2015, 23, 208-212. [CrossRef]

238. Liu, B.; Wang, L.; Zou, J.H.; Tao, H.; Su, Y.J.; Gao, D.Y.; Xu, M.; Lan, L.F.; Peng, J.B. Investigation on spacers and structures: A simple but effective approach toward high-performance hybrid white organic light emitting diodes. Synthetic Met. 2013, 184, 5-9. [CrossRef]

239. Liu, B.; Lan, L.; Zou, J.; Peng, J. A novel organic light-emitting diode by utilizing double hole injection layer. Acta Phys. Sin. 2013, 62, 087302.

240. Son, Y.H.; Kim, Y.J.; Park, M.J.; Oh, H.Y.; Park, J.S.; Yang, J.H.; Suh, M.C.; Kwon, J.H. Small single-triplet energy gap bipolar host materials for phosphorescent blue and white organic light emitting diodes. J. Mater. Chem. C 2013, 1, 5008. [CrossRef]

241. Zhang, D.; Cai, M.H.; Zhang, Y.G.; Zhang, D.Q.; Duan, L. Sterically Shielded Blue Thermally Activated Delayed Fluorescence Emitters with Improved Efficiency and Stability. Mater. Horiz. 2016, 3, 145-151. [CrossRef]

242. Zhang, D.; Duan, L.; Li, C.; Li, Y.; Li, H.; Zhang, D.; Qiu, Y. High-Efficiency Fluorescent Organic Light-Emitting Devices Using Sensitizing Hosts with a Small Singlet-Triplet Exchange Energy. Adv. Mater. 2014, 26, 5050-5055. [CrossRef] [PubMed]

243. Masui, K.; Nakanotani, H.; Adachi, C. Analysis of exciton annihilation in high efficiency sky-blue organic light-emitting diodes with thermally activated delayed fluorescence. Org. Electron. 2013, 14, 2721-2726. [CrossRef]

244. Dameron, A.A.; Davidson, S.D.; Burton, B.B.; Carcia, P.F.; Mclean, R.S.; George, S.M. Gas Diffusion Barriers on Polymers Using Multilayers Fabricated by $\mathrm{Al}_{2} \mathrm{O}_{3}$ and Rapid $\mathrm{SiO}_{2}$ Atomic Layer Deposition. J. Phys. Chem. C 2008, 112, 4573-4580. [CrossRef]

245. Seo, S.-W.; Jung, E.; Seo, S.J.; Chae, H.; Chung, H.K.; Cho, S.M. Toward fully flexible multilayer moisture-barriers for organic light-emitting diodes. J. Appl. Phys. 2013, 114, 143505. [CrossRef]

246. Park, J.-S.; Chae, H.; Chung, H.K.; Lee, S.I. Thin film encapsulation for flexible AM-OLED: a review. Semicond. Sci. Technol. 2011, 26, 034001. [CrossRef]

247. Kim, D.Y.; Park, J.H.; Lee, J.W.; Hwang, S.; Oh, S.J.; Kim, J.; Sone, C.; Schubert, E.F.; Kim, J.K. Overcoming the fundamental light-extraction efficiency limitations of deep ultraviolet light-emitting diodes by utilizing transverse-magnetic-dominant emission. Light Sci. Appl. 2015, 4, e263. [CrossRef]

248. Xiao, P.; Huang, J.; Yan, D.; Luo, D.; Yuan, J.; Liu, B.; Liang, D. Emergence of Nanoplatelet Light-Emitting Diodes. Materials 2018, 11, 1376. [CrossRef] [PubMed]

249. Xiao, P.; Huang, J.; Dong, T.; Xie, J.; Yuan, J.; Luo, D.; Liu, B. Room-temperature Fabricated Thin-Film Transistors Based on Compounds with Lanthanum and Main Family Element Boron. Molecules 2018, 23, 1373. [CrossRef]

250. Al-Asbahi, B.A.; Jumali, M.H.H.; AlSalhi, M.S. Enhanced Optoelectronic Properties of PFO/Fluorol 7GA Hybrid Light Emitting Diodes via Additions of TiO2 Nanoparticles. Polymers 2016, 8, 334. [CrossRef]

251. Shih, H.; Chen, Y.; Chu, Y.; Cheng, C.; Chang, F.; Zhu, C.; Kuo, S. Photo-Crosslinking of Pendent Uracil Units Provides Supramolecular Hole Injection/Transport Conducting Polymers for Highly Efficient Light-Emitting Diodes. Polymers 2015, 7, 804-818. [CrossRef]

(C) 2019 by the authors. Licensee MDPI, Basel, Switzerland. This article is an open access article distributed under the terms and conditions of the Creative Commons Attribution (CC BY) license (http:/ / creativecommons.org/licenses/by/4.0/). 